\title{
Comparison of Fiscal and Distributional Effects of VAT Exemptions in Korea and Japan
}

\author{
Myung Jae Sung*
}

\begin{abstract}
This paper estimates and compares fiscal and distributional effects of Korean and Japanese VAT exemptions. VAT exemptions have two types of fiscal effects on revenue: they lead to reductions in VAT revenue via the output tax and revenue increases via the undeducted input tax through cascading effects. The results of input-output analyses for both countries indicate that the former effect outweighs the latter, reducing VAT revenue but that the exemptions mitigate the distributional regressivity of its incidence. In Korea in particular, the expansion of an aged population means there are more individuals affected by VAT regressivity, as most members of this population belong to low-income deciles, mainly because they are retirees. As is suggested by the life-cycle hypothesis, older populations are likely to have higher propensity to consume than younger ones. In Japan, the VAT was supposed to increase from $8 \%$ to $10 \%$ in October 2016, having already increased from 5\% to $8 \%$ in April 2014. The additional increase was expected to exacerbate the negative impact of the VAT on income redistribution. For this reason, it has been repeatedly postponed, and now is not expected to take effect until October 2019. The growing socioeconomic resistance of the Japanese people to the VAT increase may require additional VAT reforms in Japan. It might, for example, need to increase tax revenue to cope with its growing national debt to GDP ratio as well as with its increasing welfare expenditure. The VAT is one of its key potential revenue sources. In addition, it might also need to broaden the scope of VAT exemptions to include more necessities at the expense of a little revenue so as to ease the potential increase in VAT regressivity expected to ensue from the October 2019 rate increase.
\end{abstract}

Keywords: VAT, incidence, exemption, population aging, redistributions

\footnotetext{
* Myung Jae Sung is a professor at the School of Economics, Hongik University. E-mail: mjaesung@hongik.ac.kr.
}

Manuscript received May 3, 2018; out for review May 24, 2018; review completed July 2, 2018; accepted July 19, 2018.

The Korean Journal of Policy Studies, Vol. 33, No. 2 (2018), pp. 1-39.

(C) 2018 by the GSPA, Seoul National University 


\section{SCOPE}

This paper analyzes the fiscal and distributional effects of VAT exemptions, considering the implications for VAT reform in Korea and the validity of expanding VAT exemptions in Japan as a means of addressing the increase in regressive VAT incidence that is expected to occur when the VAT rate increases to $10 \%$ in October $2019 .{ }^{1}$ This paper primarily aims to compare the VAT burden by income group along with its fiscal and distributional effects in Korea and Japan, whose systems differ in terms of the scope of VAT exemptions: Japan allows for exemptions only in limited areas such as housing services and services provided by government-related institutions, while in Korea many goods and services, ranging from necessities, education, housing, and medical, financial, and broadcasting services, among others, are exempt from the tax. This paper does not consider policy issues pertaining to the validity of VAT exemptions on specific services but rather the fiscal and distributional effects of VAT rate increases and VAT exemptions. ${ }^{2}$

The paper estimates both nominal burdens as well as effective burdens, including the hidden burdens that follow from cascading effects, through an input-output (IO) analysis. Counterfactual microsimulation analyses are conducted to analyze distributional impacts of broadening the scope of VAT exemptions and the effect of population aging on the regressivity of VAT incidence. An IO analysis is useful for capturing behavioral responses of consumers induced by a substitution effect, an effect that can be measured by estimating effective VAT burdens by sector from input coefficients. Estimation of income effect is not feasible in this paper. ${ }^{3}$

Korea introduced the VAT in July 1977, making it the first Asian country to do so, with a flat rate of $10 \%$. It is widely well known that the VAT is regressive with

1. This paper does not address a zero rate of VAT because a zero rate is not applicable to goods for domestic consumption in Korea and Japan.

2. The primary reason I compare the VAT burden in Korea and Japan is due to the similarity in tax policy in both countries. Being geographically very close, they have often adopted tax systems from each other based on their performance in the other country. VAT is an example. It was introduced in 1977 in Korea with ample exemptions to prevent potential regressivity. When Japan followed Korea and introduced the VAT in 1989 it allowed for minimal exemptions to mitigate the negative revenue impact of VAT exemption. As a result, the two countries have opposite VAT exemption systems. There are advantages and disadvantages to their differing VAT systems. This paper aims to investigate these.

3. Alternatively, a CGE analysis, for instance, could be fruitful for revealing the income effect, but at the expense of substitution effect. Technical difficulties make it impossible to include both income and substitution effects in a single model. 
respect to income and that it thus has a negative effect on income redistribution. Korea allowed ample VAT exemptions, particularly for necessity goods and services, to mitigate the negative effects induced by the regressivity of VAT because exemptions on necessities usually reduce VAT burdens on low-income individuals/ households relatively more than those on high-income ones. A wide range of VAT exemptions inevitably leads to revenue loss. Korea is expecting very rapid population aging. It also needs to prepare for the reunification of the Korean peninsula in the future. Addressing these issues will produce a huge fiscal burden, and the VAT is a key revenue sources. However, the large number of exemptions significantly erodes the VAT base and its revenue. There is thus a tradeoff between a worry about the inequity caused by a regressive VAT and the anticipated growing fiscal burden that the VAT is expected to cover.

Japan has the least allowance of VAT exemptions as well as the lowest single rate in the world. Unlike in Korea, the distributional impact of regressive VAT incidence has yet to become a topic of serious socioeconomic debate in Japan. That may be because the VAT rate has been too low to draw close attention from the general public. The rate was only $3 \%$ when the VAT was first introduced in Japan in 1989, rising to 5\% in April 1997. It remained at 5\% until March 2014, one of the lowest VAT rates in the word and far below the revenue maximizing rate, judged from the viewpoint of Matthews and Lloyd-Williams (2010). It seemed there was ample room for an increase in the Japanese VAT rate. According to the Japanese Ministry of Finance, the ratio of general government gross debt to GDP was 244.5\% in 2013, which was quite high. ${ }^{4}$ As a means of mitigating public debt, the Abe administration decided to raise VAT rate, increasing it to 8\% in April 2014.

The government planned to increase the rate to $10 \%$ in October 2015, but then it decided to postpone the increase until April 2017 primarily due to the growing concerns about tax resistance from the public and consumption shocks induced by the repeated rate increases. In the fact of ongoing resistance and economic shocks, the Abe administration recently decided to postpone the increase in VAT rate once again until October 2019. It also announced that the VAT rate on food would be fixed at

4. According to https://tradingeconomics.com/japan/government-debt-to-gdp, the Japanese government's gross debt to GDP ratio has risen very sharply recently.

Japanese Government's Gross Debt to GDP, 2008-17

(in \%)

\begin{tabular}{l|l|l|l|l|l|l|l|l|l|l}
\hline & 2008 & 2009 & 2010 & 2011 & 2012 & 2013 & 2014 & 2015 & 2016 & 2017 \\
\hline Gross Debt/GDP & 191.8 & 201.2 & 215.8 & 231.6 & 238.0 & 244.5 & 249.1 & 248.0 & 250.4 & 253.0 \\
\hline
\end{tabular}

Sources: Tradingeconomics.com and Japanese Ministry of Finance 
the current rate of $8 \%$ even after the planned but postponed increase in the VAT rate to $10 \%$. If this happens, the Japanese VAT system will thus shift from a single-rate to a multi-rate system. The increases in the VAT burden are not negligible. Any further increase may receive considerable attention because it may yield further inequality in post-VAT income. Adjustment in the scope of VAT exemptions may be an option for mitigating the regressivity the planned rate increase is expected to induce and for preventing tax resistance.

Recent changes in the VAT in Europe, compounded by the regressivity of VAT incidence, rapidly increased burdens, particularly on low-income households, thereby slightly compromising vertical equity. In Japan, the recent increase in VAT rate may similarly reinforce the regressivity of the consumption tax.

The recent phenomenon of population aging, which results in given populations having greater numbers of older individuals, is believed to accelerate and reinforce regressive VAT incidence. Older individuals are likely to have higher propensity to consume than younger ones. In addition, the older the individual, the more likely he or she is to belong to lower income deciles, mainly because of retirement, a point more fully addressed in the data section of the paper and also documented in table A.4.

Other factors that play an important role in determining the regressivity of VAT incidence are the scope of VAT exemptions and whether a VAT system is single- or multi-rate. Necessities are often exempt from the VAT, and this mitigates the VAT burden on low-income households relatively more than on high-income ones at the expense of the VAT base, resulting in reduced VAT regressivity. Korea is a country with ample VAT exemptions, particularly exemptions aimed at promoting vertical equity. In addition, reduced VAT rates on certain goods, particularly necessities, often play a similar role in mitigating VAT burdens on the poor relatively more. A system of multiple VAT rates has been widely adopted by many countries, particularly by early VAT adopters in Europe.

In sum, the VAT is generally regressive with respect to income, to the extent of the law of diminishing marginal propensity to consume. Exemptions or zero rating are often used in many countries to cope with the regressive VAT. The scope of VAT exemptions for domestic consumption is different across countries, and thus understanding how these exemptions work requires that they be investigated on a case-bycase basis. Here I analyze those of Korea and Japan, which share a culture steeped in Confucianism but have adopted very different VAT exemption systems.

The rest of this paper is organized as follows. First, I review the relevant literature, describe the basic structures of the VAT in Korea and Japan, and outline the paper's arguments. I next briefly explain the methods and data sets, and then I pres- 
ent the results. I conclude with a brief discussion on policy implications for VAT exemptions.

\section{LITERATURE SURVEY}

It has long been widely accepted and validated by empirical studies (e.g., Pechman \& Okner, 1974) that VAT incidence is regressive with respect to income, widening the relative income gap between households. Regressive VAT incidence stems primarily from the law of diminishing marginal propensity to consume (MPC). However, some recent studies have found that VAT incidence may not be regressive but proportional or mildly progressive with respect to income, which is inconsistent with common public perception. Arsić and Altiparmakov (2013) have recently argued that the claim that VAT incidence is regressive is misguided or overstated, particularly in connection with emerging European countries such as Serbia. They provide a survey of such countries, focusing on the problem of bias that results from the underreporting of income, probably stemming from the widely epidemic shadow economy in the region they consider, and on the widespread presence of the ownsource small-farming production of food and related in-kind consumption in Serbia (Arsi and Altiparmakov 2013, pp. 176-177). They find that this type of bias can considerably distort the estimated regressivity of the VAT. Given this income underreporting in conjunction with ample food production for self-consumption, VAT incidence may in fact be proportional or mildly progressive in Serbia. However, this proposition does not yet have enough support to provide a concrete foundation for the proportionality or mild progressivity of VAT incidence in general. As a result, the validity of this claim needs to be tested on a case-by-case basis.

There are several other studies dealing with the regressivity of the VAT burden. Using IO analysis to generate a simulation, Tamaoka (1994) analyzes, the effects of changes in VAT rates in Japan and the shift from the existing single-rate system with the smallest range of exemptions to a multi-rate system including exemptions for selected necessities. He finds that Japan's VAT is regressive with respect to income as well as consumption and also that VAT exemptions on necessities do not eliminate the regressivity of VAT but only reduce VAT burdens for all income groups in Japan. Liberati (2001) analyzes the anticipated effect of revenue neutral changes in the move from a four-rate to a three-rate and then a two-rate VAT system enacted in late 1990s in Italy, undertaken in accordance with EU directives aimed at creating a single VAT structure across EU countries. He finds that replacing the preexisting multi-rate system with a two-rate revenue-neutral VAT system would increase wel- 
fare, despite the regressivity of VAT burdens in Italy. Crossley, Low, and Wakefield (2009) estimate the revenue and distributional effects of a temporary VAT cut from $17.5 \%$ to $15 \%$ for 13 months until the end of 2009 in the United Kingdom. They find that effect on income from the reduction of the rate is negligibly small but that the intertemporal substitution effect between periods induced by the rate change is quite sizable, amounting to about $1 \%$ of total consumption. The temporary rate change is regressive since the temporarily reduced rate applies mostly to luxuries and, thus, results in reduction of VAT burden on higher income groups. Barrell and Weale (2009) also study the same topic and reach similar conclusions.

Caspersen and Metcalf (1994), Creedy (1998), and Decoster, Loughrey, O’Donoghue, and Verwerft (2010), approach proportional and progressive VAT incidence in a completely different way. Caspersen and Metcalf (1994) consider what effects the introduction of the VAT into the United States might have using the data sets of the Panel Study of Income Dynamics and the Consumer Expenditure Survey. They find that using annual income to measure economic well-being makes a VAT look quite regressive, that a broad-based VAT would be only modestly regressive under two different measures of lifetime income, and that using current consumption as a proxy for lifetime income makes a VAT proportional. Creedy (1998) and Decoster et al. (2010) examine lifetime VAT incidence instead of its annual incidence and conclude that the former is proportional or mildly progressive, unlike the latter.

Fiscal reliance on the VAT has increased sharply in European countries, particularly in the last decade (see OECD, 2011, and European Commission, 2011). ${ }^{5}$ VAT revenue to GDP ratios have increased sharply as a result of increases in VAT rates. Of course, an increase in the tax rate does not always induce a revenue increase, particularly above a certain level, as the well-known Laffer curve shows. Conducting a regression analysis on the VAT in developed countries, Matthews and Lloyd-Williams (2010) explore whether or not the VAT rate has already reached its maximum limit, yielding the highest revenue to GDP ratio possible, using the ratio of VAT revenue to GDP as a dependent variable and the standard rate of VAT and its square term, the number of VAT rates, and the ratio of money supply to GDP ratio as major explanatory variables. They find that the revenue to GDP ratio is positively correlated with the standard rate and negatively with its square term, both significantly implying that current rates are close to the revenue-maximizing rate of VAT in most countries under consideration, which they estimate to be about $20 \%$.

5. According to International Tax Dialogue's The Value Added Tax: Experiences and Issues (2012), an increasing number of countries have adopted the VAT. Figure 1 of the report shows about 140 countries having the VAT as of 2009. 


\section{THE VAT SYSTEM IN KOREAAND JAPAN}

Most countries in Western Europe have multiple VAT rates. By contrast, Korea and Japan had single rates of $10 \%$ and $8 \%$ as of January 1, 2018, respectively. Korea is one of the countries with the widest range of VAT exemptions, whereas Japan is one of the countries with the narrowest. Table A.1 in the appendix compares the scope of VAT exemptions in the two countries.

As shown in table A.1, Korea allows a wide range of VAT exemptions for numerous goods and services, including unprocessed food products, medical services, educational services, financial services, government/public services, tap water, and books, among others, whose purpose is largely to secure vertical equity and thereby compensate for regressive VAT incidence with respect to income. These are mainly necessities, and the government exempts them from the VAT in order to enhance the redistributive effect by reducing VAT burdens on those in low-income households with income-inelastic demand.

VAT is rarely exempt in Japan. Only a few selected goods and services are subject to VAT exemption, including certain medical and government/public services. As a result, the distribution of VAT burdens is similar to that of the consumption expenditure in Japan.

Neither Korea nor Japan have a VAT zero rate for domestic consumption, unlike many other OECD member countries (see OECD, 2013); for example, unprocessed food is VAT zero-rated in the United Kingdom, Canada, and Australia, but not in Korea or Japan. The two countries allow a zero rate only for limited purposes such as exported goods, services rendered outside Korea or Japan, international transportation services, and other goods and services supplied for foreign exchange earnings (for example, duty-free purchases carried abroad for nonresidents and those supplied to foreign diplomats or diplomatic organizations). For this reason, I only address VAT exemptions in Korea or Japan.

Korea and Japan differ with respect to the scope of VAT exemptions, but they both have adopted a single-rate VAT structure. The difference in the exemptions they allow is closely related to the apparent relative difference in distributional equity as well as in the VAT to GDP ratio and in VAT rates (5\% until March 31, 2014, and then $8 \%$ starting on April 1, 2014, in Japan vs. $10 \%$ in Korea). According to the OECD (2017), the VAT revenue to GDP ratios for 2015 were $4.2 \%$ in Japan and $3.8 \%$ in Korea, respectively. ${ }^{6}$ Although the nominal VAT rate was $25 \%$ higher in

6. The VAT to GDP ratio was $3.8 \%$ in 2015 , exceptionally low for Korea. It had been stable at about 4.2\% from 2011 until 2015, according to the Korean Ministry of Finance and Strategy. 
Korea than in Japan, the VAT to GDP ratio has recently been lower in Korea than in Japan. This seemingly contradictory phenomenon is mainly due to the huge difference in the scope of VAT exemptions in the two countries.

Korea emphasizes the redistributive function of the VAT and thus allows a wide range of exemptions, particularly for necessities. Because necessities are consumed more by the poor than by the rich, exemptions for necessities are likely to reduce VAT burdens on the poor relatively more. In this regard, the regressivity of VAT incidence can be mitigated, but it inevitably erodes the VAT base and reduces revenue.

By contrast, Japan emphasizes the allocative efficiency of resources as a way to prevent the distortionary effect of VAT exemptions and allows almost no exemptions at the expense of foregone equity. Until March 31, 2014, it had the lowest VAT rate in the world, at $5 \%$, and so Japanese consumers did not perceive it as a substantial burden. Thus, the regressive effect of VAT incidence in Japan did not cause a serious problem with respect to income distribution or the vertical equity of VAT incidence up to that point. However, if the proposed increase to $10 \%$ takes place as planned in October 2019, then the VAT burden would be no longer negligible, and the problem of regressive VAT incidence may receive closer attention.

There may be some tradeoff between vertical equity (that is, a redistributive effect) and allocative efficiency, particularly with respect to VAT exemptions. In addition, the age structure of the population may determine the distribution of VAT incidence owing to different consumption patterns across age groups. Older individuals are more likely to consume necessities than younger ones. Therefore, VAT exemptions for necessities may have a significant effect on income redistribution, depending on the age structure of the population.

Arsić and Altiparmakov's (2013) finding that the VAT incidence is not regressive but roughly proportional to income raises the question of what causes the neutrality of VAT incidence despite the regressivity predicted by the law of diminishing MPC. The answer may be that such neutrality owes to a country's broad VAT exemptions. Examination of changes in VAT exemptions and the effects of population aging may provide useful information regarding the VAT policies of Korea and Japan. Differ-

\begin{tabular}{c|c|c|c|c|c}
\multicolumn{6}{c}{ Korea's and Japan's VAT Revenue/GDP Ratio, 1990-2015 } \\
\hline \\
\hline Korea & 1990 & 2000 & 2010 & 2014 & 2015 \\
\hline Japan & 1.2 & 2.3 & 2.56 & 3.7 & 4.2 \\
\hline
\end{tabular}

Note: What is counted as VAT revenue for the purposes of this table is based on the definition of VAT supplied by OECD heading 5111.

Source: OECD (2017, table 3.14, p. 63) 
ences in the scope of VAT exemptions and the age structure of the population may have an effect on income redistribution, on allocative efficiency, and on VAT revenue in Korea and Japan. I estimate these effects through counterfactual analyses for the two countries, using microsimulation methods in conjunction with IO analyses to produce the counterfactual scenarios.

For Korea, I estimate the redistributive effects of VAT exemptions by considering what would happen if Korea adopted the Japanese VAT exemption system. I conduct another simulation to analyze the effect of aging on VAT distribution and on income redistribution. Here I substitute the sample weight of Korean households by age group with that of Japanese households.

For Japan, I analyze the effect of broader VAT exemptions for necessities on income redistribution through a counterfactual analysis using similar counterfactual microsimulation methods. I conduct a simulation by assuming a scenario in which the Korean VAT exemption system is implemented in Japan. I compare the results with those generated under Japan's current system; this information may prove useful for addressing the anticipated increase in VAT burdens from the planned increase in the VAT rate.

A change in the scope of VAT exemptions inevitably impacts revenue both directly and indirectly. In a direct revenue effect, there is an observable change in revenue from the increased output tax net of any (unobserved) input tax. With an indirect revenue effect, there is an unobservable change in revenue caused by cascading effects generally embedded in the input tax that is largely not deducted in exempt sectors. These effects are not easy to estimate unless direct and induced changes in input tax are known. In fact, changes in input tax are generally not observable, and therefore an IO analysis is required to identify and estimate unobserved factors.

\section{METHODS OF ANALYSIS AND DATA}

\section{Methods}

I estimate effective VAT rates by sector, the (effective) incidence of the VAT by income decile, and the effects of the VAT on income redistribution using IO analyses, microdata analyses, and simulation methods, among others. 


\section{Procedures}

I examine the fiscal and distributional characteristics of the VAT systems in Korea and Japan and estimate the effects of changes in the scope of VAT exemptions on revenue and vertical equity. I assume in employing $\mathrm{IO}$ analyses and microsimulations that it is possible to substitute the VAT systems of one country for the other. This procedure is briefly explained as follows. In the first step, I estimate nominal and effective VAT incidences for Korea and Japan using effective VAT rates by sector, which are in turn based on parameter estimates of effective VAT rates by sector derived from an IO analysis. In the second step, I conduct simulations to estimate the effects of changes in the scope of VAT exemptions on VAT revenue in Korea and Japan through an IO analysis. Revenue effects are decomposed by factor, including cascading effects. In the third step, I conduct microsimulations on the scope of VAT exemptions in Korea and Japan in order to estimate distributional effects. I compare the vertical equity of VAT exemptions in the two countries in terms of percentage changes in the Gini coefficients. I then turn to policy implications.

\section{The Estimation of Effective VAT Rates by Sector}

I estimate effective VAT rates by sector through an IO analysis. Effective VAT burdens for a given VAT-exempt sector consist of VAT burdens on inputs that are not deducted, that is, the sum of VAT burdens explicitly or implicitly imposed on VAT-taxable intermediate inputs as well as those burdens implicitly embedded in other VAT-exempt intermediate inputs. Effective VAT burdens in a VAT-taxable sector consist of two components: (effective) VAT burdens on total demand (i.e., the output tax) and those burdens embedded in VAT-exempt intermediate inputs. The effective VAT rate is defined as the ratio of effective VAT burdens to total supply (or total demand, particularly in equilibrium). In general, this rate is higher than the nominal VAT rate in taxable sectors and between $0 \%$ and the nominal rate for exempt sectors.

I use the methods in Gottfried and Wiegard (1991), Ebrill et al. (2001) and Marks (2003) to estimate VAT rates by sector. In the first step, nominal VAT rates are set as initial values for each sector: $0 \%$ and the face rate $(10 \%$ for Korea and $8 \%$ for Japan, both for the year 2014) for exempt and taxable sectors, respectively. In the second step, input VAT burdens from (intermediate) inputs and output VAT burdens are calculated based on initial values of effective VAT rates. Then effective burdens and effective rates are calculated for each sector such that 
ER $=\left\{\begin{array}{c}\text { inputs from taxed sectors } \times \text { the ER of inputs from taxed sectors } \div \text { total supply (exempt sectors) } \\ \text { or the VAT on inputs from exempt sectors } \div \text { total supply } \\ \text { (taxed sectors) }\end{array}\right.$

In the third step, estimated effective VAT burdens and rates are set as initial values for the next step. Then the second and third steps are repeated until estimated effective rates converge. Converged estimates are the final estimates of effective VAT rates by sector.

\section{Technical Methods for Microsimulations}

Simulations for population aging require the substitution of sample weights with those of the target by age group. It is easy to do this with raw data but not with the aggregate data, available only by decile, quintile, gender, or age group, from the Japanese National Survey of Family Income and Expenditure (NSFIE) that I used for this analysis. One way to overcome this difficulty is to substitute the aggregate information within the target group, including sample weights by age group, for the decile distribution. This section illustrates this method.

Let $\mathrm{z}_{i j}^{k}$ be the average expenditure per household for the $\mathrm{kth}$ good (service) for the ith age and the jth income decile group and define its sample conditional means as follows:

$$
\begin{aligned}
& \overline{\mathrm{z}}_{\cdot j}^{k}=\sum_{i} \mathrm{z}_{i j}^{k} \cdot q_{i j}^{o} \text { where } q_{i j}^{o}=w_{i j} / w_{\cdot i} \text { and } w_{\cdot i}=\sum_{i} w_{i j} \text { and } \\
& \overline{\mathrm{z}}_{i .}^{k}=\sum_{j} \mathrm{z}_{i j}^{k} \cdot q_{i j}^{*} \text { where } q_{i j}^{*}=w_{i j} / w_{i} . \text { and } w_{i} \cdot=\sum_{j} w_{i j} .
\end{aligned}
$$

Note, for example, that $w_{\cdot j}=0.1$ and 0.2 for decile and quintile distributions, respectively. Statistics Japan provides detailed information in the NSFIE by income quintile/decile, area of residence, dwelling type, industry, and occupation, among others, for every fifth year between 1994 and 2014.7 Unfortunately, information on the joint distribution of $\mathrm{z}_{i j}^{k}$ for $\mathrm{i}$ and $\mathrm{j}$ is not available because its raw data sets are not provided. Instead, information is available only on its marginal distributions $\bar{Z}_{. j}^{k}$ and $\overline{\mathrm{Z}}_{j}^{k}$.

$$
\overline{\mathbf{z}}^{k}=\sum_{i} \sum_{j} \mathbf{z}_{i j}^{k} \cdot w_{i j}=\left\{\begin{array}{c}
\sum_{j} \sum_{i} \mathbf{z}_{i j}^{k} \cdot q_{i j}^{o} \cdot w_{\cdot j}=\sum_{j} \overline{\mathbf{z}}_{\cdot j}^{k} \cdot w_{\cdot j} \\
\text { or } \\
\sum_{i} \sum_{j} \mathbf{z}_{i j}^{k} \cdot q_{i j}^{*} \cdot w_{i \cdot}=\sum_{i} \overline{\mathbf{z}}_{i}^{k} \cdot w_{\cdot i}
\end{array}\right.
$$

7. See www.stat.go.jp/english/data/zensho/index.htm for more detail. 
Statistics Japan provides information on the marginal expenditure of household consumption on goods (including services) either by income decile or by age group and on the joint distribution of households with respect to their age and decile. Therefore, $\overline{\mathrm{z}}_{. j}^{k}$ for all $\mathrm{j}, \overline{\mathrm{z}}_{i}^{k}$ for all $\mathrm{i}$, and $w_{i j}$ for all $\mathrm{i}$ and $\mathrm{j}$ are available.

If $\mathrm{z}_{i j}^{k}$ were available for all $\mathrm{i}$ and $\mathrm{j}$, then experimental simulations of population aging could be executed by varying $w_{i j}$ to obtain a new decile distribution $\bar{z}_{\cdot j}^{k}$ for $\mathrm{j}$. However, $\mathrm{z}_{i j}^{k}$ is not known. Without further information, simulation analyses cannot be conducted because the number of variables exceeds that of unique equations, a result of insufficient degrees of freedom. In this case, many multiple combinations of solutions for $\mathrm{z}_{i j}^{k}$ can be obtained for some given $w_{i j}$ for each $\mathrm{j}$, resulting in the indeterminacy of a simultaneous equation system. Another assumption is required to avoid indeterminacy, namely one that reduces the dimension of parameter space such that values of $\mathrm{z}_{i j}^{k}$ for all age groups within each income decile group are propor-

tional to each for all $\mathrm{j} .{ }^{8} \mathrm{In}$ fact, this assumption is equivalent to $\frac{\mathrm{z}_{s j}^{k}}{\mathrm{z}_{t j}^{k}}=\frac{\mathrm{z}_{s .}^{k}}{\mathrm{z}_{t .}^{k}}$ for all $\mathrm{s}$ and $\mathrm{t}$ and for all $\mathrm{j}$.

Here changes in $w_{i j}$ are known by assumption. However, individual $\mathrm{z}_{i j}^{k}$ values for each value of the ith group are not known for some given $\mathrm{j}$. Therefore, it is assumed that $\mathrm{z}_{i j}^{k}=\mathrm{z}_{i}^{k}$. without loss of generality.

\section{Data}

The aforementioned differences in the scope of VAT exemptions between Korea and Japan are reflected in revenue (in particular, VAT to GDP ratio) as well as in redistributive effects.

IO tables for the two countries are used to estimate effective VAT rates by sector, total VAT revenues, and cascading effects induced by VAT exemptions. ${ }^{9}$ These are parameter estimates used in policy simulations, including changes in VAT exemptions by sector. Here induced changes in effective VAT rates by sector and VAT revenue are also estimated. There are several versions of IO tables. Among these, I adopt a 384-sector IO table for the analysis for Korea and a 399-sector IO table for that of Japan. ${ }^{10}$

8. This assumption can be expanded such that the relative ratio of the value corresponding to a specific age group is the same across all deciles, including all households, without loss of generality.

9. IO tables for the year 2010 come from the websites of the Statistics Bureau of Japan (http:// www.stat.go.jp/english/data/io/index.htm) and the Bank of Korea (http://ecos.bok.or.kr/ EIndex_en.jsp).

10. The Statistics Bureau of Japan provides a 518 -sector (row) $\times 405$ sector (column) IO table on its website. I have regrouped these into 399 individual sectors. 
Table 1. Descriptive Statistics: HIES and the NSFIE, 2014 (in thousand \#/\%)

\begin{tabular}{l|c|c|c|c}
\hline & \multicolumn{2}{|c|}{ Korea } & \multicolumn{2}{c}{ Japan } \\
\hline Household Size & 2.75 & & 2.39 & \\
\hline Number of Income Earners & 1.25 & & 1.14 & \\
\hline Head & & & & \\
\hline Age & 52.34 & & 57.9 & \\
\hline Male & 72.3 & & 76.4 & \\
\hline Female & 27.7 & & 23.6 & \\
\hline Share of Automobiles Owned & 63.0 & & 73.6 & \\
\hline Gross Income & 48,088 & & 5,331 & \\
\hline Consumption & 26,534 & $(100.0)$ & 3,053 & $(100.0)$ \\
\hline Food & 3,765 & $(14.2)$ & 744 & $(24.4)$ \\
\hline Alcoholic Beverages and Tobacco & 302 & $(1.1)$ & & \\
\hline Housing & & & 234 & $(7.7)$ \\
\hline Heating and Water & & & 215 & $(7.0)$ \\
\hline Housing, Heating and Water & 2,930 & $(11.0$ & & \\
\hline Clothing & 1,727 & $(6.5)$ & 125 & $(4.1)$ \\
\hline Furniture, Utensils, and Related Services & 1,053 & $(4.0)$ & 104 & $(3.4)$ \\
\hline Health and Medical Services & 1,859 & $(7.0)$ & 132 & $(4.3)$ \\
\hline Transportation & 3,489 & $(13.2)$ & & \\
\hline Communication & 1,514 & $(5.7)$ & & \\
\hline Transportation and Communication & & & 453 & $(14.8)$ \\
\hline Reading and Recreation & 1,539 & $(5.8)$ & 320 & $(10.5)$ \\
\hline Education & 2,673 & $(10.1)$ & 111 & $(3.6)$ \\
\hline Accommodation and Restaurants & 3,438 & $(13.0)$ & & \\
\hline Other Consumption Expenditure & 2,250 & $(8.5)$ & 614 & $(20.1)$ \\
\hline Nonconsumption Expenditure & 4,490 & & 803 & \\
\hline Nos: & & & \\
\hline
\end{tabular}

Notes: 1. All figures are based on the author's own calculations.

2. The calculations reflect the exchange rate as of December 31,2009 , in which $¥ 100=¥ 1,256.10$.

3 . Figures in parentheses indicate what percentage of total consumption the number represents.

A microsimulation analysis generally requires a micro data set such as a consumer survey. In this paper, I use two consumer surveys, the Household Income and Expenditure Survey (HIES) for Korea and the National Survey of Family Income and Expenditure (NSFIE) for Japan, both for the year 2014. The data year is a little out of date, but 2014 is the most recent year for which the survey data sets and most recent IO tables are available for both countries. ${ }^{11} \mathrm{I}$ use a raw data set in the analysis

11. Recently in Japan, an IO table for 2011 was released. Unfortunately, however, it was not usable because about 40 sectors, including tobacco products, had zero entries for intermediate 
for the HIES, but because such a data set is not available for the NSFIE, for my analysis of it, I use only aggregate variables by income quintile and income decile, age group, and gender, among others. ${ }^{12}$ The analysis based on the NSFIE may thus be limited in certain instances, particularly in measuring inequality, because there are only 10 observations available for decile information. I used these two consumer surveys to estimate distributional characteristics as well as to conduct simulations.

Table 1 reports descriptive statistics based on the HIES and the NSFIE for 2014 for Korea and Japan, respectively. The average household size is 2.75 individuals in Korea and 2.39 in Japan. The average number of income earners per household is slightly higher in Korea (1.25) than in Japan (1.14). This is mainly because of the difference in the average household size.

The average ages of household heads are 52.34 in Korea and 57.9 in Japan. This large difference reflects different degrees of population aging between the two countries. The average propensity to consume (APC) is similar: $0.552(=26,534 \div 48,088$ in thousand $¥)$ in Korea and 0.573 in Japan $(=3,053 \div 5,331$ in thousand $¥)$.

Figure 1. Population Distribution by Age Group in Korea and Japan, 2014

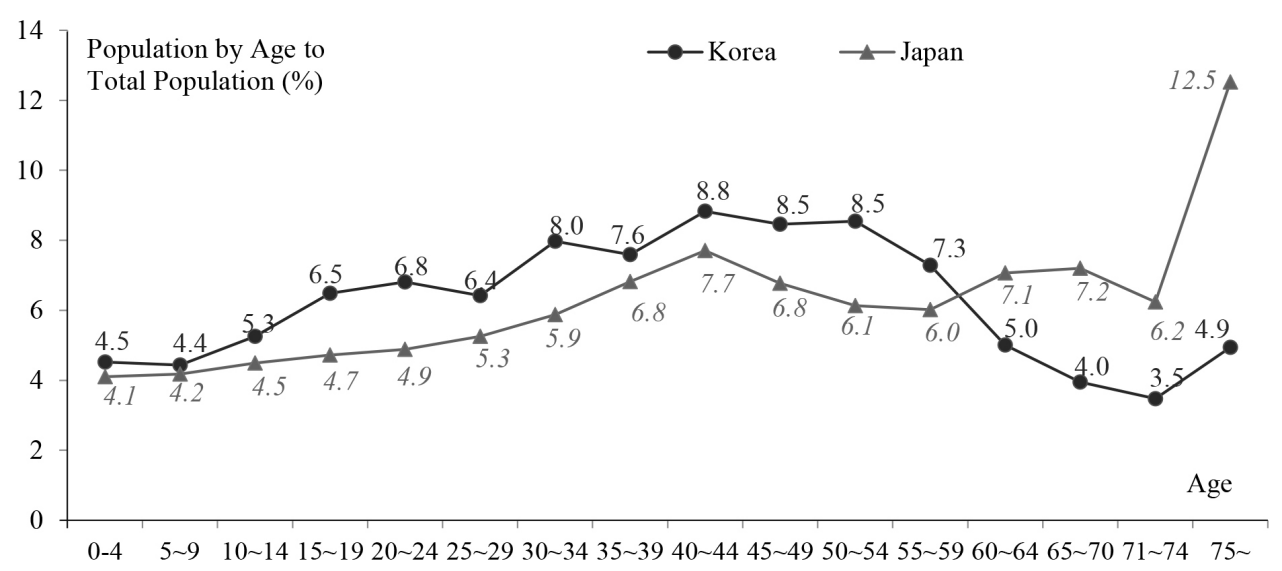

Note: All figures come from the official websites of the statistical offices of Korea and Japan (Statistics Korea, http://kostat.go.kr/portal/english/news/1/17/1/index.board, and the Statistics Bureau of Japan, www.stat.go.jp/english/data/jinsui/index.htm))

inputs. The most recent reliable table is for 2010. In order to be able to analyze the effective VAT rates by sector using the 2014 NSFIE, I have had to adjust the 2010 IO table proportionally by using the nominal GDP growth rate between 2010 and 2014 in Japan.

12. See Statistics Bureau of Japan, www.stat.go.jp/english/data/zensho/index.htm. 
Figure 1 shows the household distribution by age in Korea and Japan. Japan has more older individuals relative to its total population than does Korea. Table 1 reports the differences in the average age of household heads. The population share of age groups up to the age of 54 is higher in Korea than in Japan, whereas this pattern is reversed for age groups of above 55 .

Table A.3 in the appendix reports the joint distribution of households by age and income decile in Korea and Japan. Noteworthy is that older households are increasingly concentrated around lower income deciles in both countries. This type of asymmetrical distribution probably reflects the fact that older individuals are often retirees with little market income and thus are more likely to belong to low-income groups.

\section{ESTIMATION RESULTS}

This section discusses the estimation and simulation results. The first part provides an analysis of revenue effects of VAT exemptions through counterfactual simulations under a hypothetical scenario in which the VAT exemption systems of Korea and Japan are replaced with each other. The next three parts estimate the distributional characteristics of VAT burdens in Korea and Japan, respectively. The last part discusses the distributional effects of changes in the scope of VAT exemptions based on the counterfactual simulations.

\section{Fiscal Effects of VAT Exemptions: VAT Revenue and Cascading Effects}

Table 2 reports the estimates of VAT revenue based on IO analyses for Korea and Japan. As of 2014, the revenue estimate for Japan is ¥17.843 trillion and its realization is $¥ 18.083$ trillion (see table A.2). The difference between estimate and realization arises largely from a difference between accrual and cash bases and is not large (only $1.3 \%$ of the revenue estimate). VAT revenue consists of direct revenue from consumption and indirect revenue from cascading effects embedded in the undeducted input tax. The share of direct revenue accounts for $92.7 \%$ of total revenue. This is quite high, mainly because the scope of VAT exemptions is limited. Hidden VAT revenue from cascading effects is generated mainly from VAT-exempt sectors.

For Korea, the VAT revenue estimate for 2014 is 62.2131 trillion, whereas its realization is $\$ 62.9745$ trillion (table A.2). Here the difference is $1.2 \%$ of the revenue estimate, which arises partly from a difference between accrual and cash bases and partly from unpaid VAT liabilities as well as estimation errors. Direct revenue 
accounts for $78.9 \%$ of total revenue, which is much lower than that for Japan $(92.7 \%)$. This difference stems mainly from the large difference in the scope of VAT exemptions between the two countries.

Table 2. Effects of Changes in VAT Exemptions on VAT Revenue in Korea and Japan

(in billion $\# /$ )

\begin{tabular}{l|rc|cc}
\hline $\begin{array}{l}\text { Based on the Current VAT Exemption } \\
\text { System (Case 1) }\end{array}$ & \multicolumn{2}{|c|}{ Korea } & \multicolumn{2}{c}{ Japan } \\
\hline Total & $62,213.1$ & $(100)$ & $17,843.4$ & $(100)$ \\
\hline direct revenue from consumption & $49,069.5$ & $(78.9)$ & $16,543.0$ & $(92.7)$ \\
\hline cascading effect & $13,143.6$ & $(21.1)$ & $1,300.5$ & $(7.3)$ \\
\hline (B1) embedded in VAT exempt sectors & $11,942.4$ & $(19.2)$ & $1,162.7$ & $(6.5)$ \\
\hline (B2) embedded in VAT taxable sectors & $1,201.2$ & $(1.9)$ & 137.8 & $(0.8)$ \\
\hline Based on a Hypothetical Scenario in Which & \multicolumn{2}{|c|}{ Korea } & \multicolumn{2}{c}{ Japan } \\
Korea's and Japan's VAT Exemption & \multicolumn{2}{|c|}{$\begin{array}{l}\text { (Japanese VAT } \\
\text { System Are Swapped Out (Case 2) }\end{array}$} & \multicolumn{2}{|c|}{ (Korean VAT } \\
\hline Total & $74,542.5$ & $(100)$ & $13,881.1$ & $(100)$ \\
\hline direct revenue from consumption & $67,052.2$ & $(90.0)$ & $11,816.5$ & $(85.1)$ \\
\hline cascading effect & $7,490.4$ & $(10.0)$ & $2,064.5$ & $(14.9)$ \\
\hline (B1) embedded in VAT exempt sectors & $7,258.9$ & $(9.7)$ & $1,804.4$ & $(13.0)$ \\
\hline (B2) embedded in VAT taxable sectors & 231.5 & $(0.3)$ & 260.1 & $(1.9)$ \\
\hline
\end{tabular}

Notes: 1. The IO analysis is based on the 2014 input-output table for Korea and on the 2010 one for Japan. In order to compensate for the gap between 2010 and 2014 for Japan, the nominal GDP growth has been used to adjust elements in the input-output table. Furthermore, the VAT rate has also been adjusted from $5 \%$ for the calendar year 2010 to $7.25 \%$ for the calendar year 2014, which is an interpolation between $5 \%$ and $8 \%$ based on the three quarters during which the increased rate was applied starting on April 1, 2014, in Japan.

2. Case 1 yields estimates based on the country's scope of VAT exemptions allowed by the 2014 VAT exemption system, whereas case 2 produces estimates based on the hypothetical scope of VAT exemptions under a scenario in which the VAT exemption systems of Korea and Japan are switched.

3. The realization of VAT revenue in 2014 is $\$ 62.9745$ trillion in Korea and $¥ 18.0827$ trillion in Japan.

4. Figures in parentheses indicate the shares to total revenues.

The lower half of table 2 shows the simulation results under the scenario in which we swap out Korea's and Japan's VAT exemption systems. When Japan's system is replaced with that of Korea, then Japan’s VAT revenue drops from $¥ 17.84$ tril- 
lion to $¥ 13.88$ trillion, a $22.2 \%$ decrease. This decrease in revenue is mainly due to a sharp reduction in direct revenue from the output VAT: $¥ 16.54$ trillion $\rightarrow ¥ 11.82$ trillion. However, the expansion of VAT exemptions increases indirect revenue (i.e., cascading effects) from $¥ 1.30$ trillion to $¥ 2.06$ trillion. This implies that the undeducted input VAT increases with the expansion of range of VAT exemptions, although the shift inevitably reduces direct revenue from the output VAT. As a result, the share of direct revenue decreases from $92.7 \%$ to $85.1 \%$, which is a little higher than the current share in Korea $(78.9 \%)$. This raises the question of why its share is higher in Japan in this hypothetical scenario than in Korea.

Two factors may account for this result: the difference in the population age structure and the difference in individuals' income level. Japan is far more aged than Korea in terms of the overall composition of the population, as shown in figure 1 . In general, older individuals are tend to have less income and to spend more of their income on food, in line with Engel's law. Thus, the aging effect generally lowers the direct revenue share. Generally speaking, VAT-taxable consumption items are more income elastic than VAT-exempt ones. Per capita GDP for 2014 is higher in Japan (US\$38,143) than in Korea (US\$27,811). ${ }^{13}$ This implies that Japanese consumers are likely to be more elastic with respect to taxable consumption items and so likely to consume more VAT-taxable items than Korean consumers. Thus, the income effect generally increases the direct revenue share. Of these, the latter may outweigh the former. Therefore, these two contradictory factors may jointly explain why the share of direct revenue becomes larger for Japan than for Korea in the simulation analysis.

Replacing the Korean VAT exemption system with that of Japan increases VAT revenue from $\$ 62.21$ trillion to $\$ 74.54$ trillion, a $19.8 \%$ increase. A sharp reduction of VAT exemptions increases direct revenue sharply from $\$ 49.07$ trillion to \#67.05 trillion, a 36.6\% increase. However, this inevitably curtails indirect revenue, leading to a decrease of $57.0 \%$, from $\$ 13.14$ trillion to $\$ 7.49$ trillion, because the shift in the scope of VAT exemptions is likely to reduce the undeducted input VAT, particularly in VAT-exempt sectors.

Although the change in the scope of VAT exemptions is symmetrical between the two countries, the relative change in VAT revenue is not symmetrical. This may be because, in addition to differences in the population age structure, consumption patterns are completely different between the two countries.

13. US $\$ 38,550$ and US $\$ 29,730$ in 2017 . These numbers come from www.imf.org/external/ pubs/ft/weo/2017/02/weodata/index.aspx. 


\section{Distribution of VAT Burdens in Korea and Japan}

\section{Effective VAT Burdens}

The average effective VAT rates for 2014 are $3.84 \%$ of income and $6.97 \%$ of consumption for Korea and $3.68 \%$ of income and $6.78 \%$ of consumption for Japan. The effective rates are slightly lower in Japan than in Korea. The differences are quite small, considering the difference in face rates at $10 \%$ and $8 \%$, respectively. The asymmetry of the differences between the effective burdens and face rates owes mainly to the vast differences in the scope of VAT exemptions in the two countries.

VAT burdens accrue based on consumption expenditure. Without exemptions, a theoretical effective VAT to consumption ratio would be identical to the face VAT rate. VAT is exempt for certain goods and services in almost all countries. Thus, effective VAT rates are generally lower than its face rates. The aforementioned effective VAT to consumption ratios are similar in Korea (6.97\%) and Japan $(6.78 \%)$. The face VAT rate is $10 \%$ in Korea, which suggests that consumption of VAT-exempt items amounts to about $30 \%\left(\fallingdotseq 11-\frac{6.97 \%}{(10 \%)}\right.$ ). The face VAT rate is $5 \%$ in the first quarter and 8\% for the other three quarters of the year in 2014 in Japan. Its annual weighted average face rate is $7.25 \%$. This implies that about consumption of VAT-exempt items accounts for about $6.5 \%\left(\doteqdot 11-\frac{6.78 \%}{(7.25 \%)}\right)$ of consumption in Japan. It can be inferred that the face VAT rate and the scope of exemptions jointly determine effective VAT burdens.

Figure 2 illustrates the effective VAT rates by income deciles in Korea and Japan in terms of income (left side) and consumption (right side). As shown in the left side of figure 2, the effective VAT to income ratios are negatively sloped to the right in both countries. This is mainly because of the law of diminishing MPC. The downward sloping distributional pattern is more apparent in Japan than in Korea: the effective VAT to income ratio is $8.39 \%$ for the first decile and decreases continuously to $2.45 \%$ for the top one in Japan, whereas it is $4.38 \%$ for the bottom decile and decreases to $3.29 \%$ for the top one in Korea. The difference in the slopes is correlated with the differences in the degrees of population aging as well as with differences in consumption patterns.

However, as shown in the right side of figure 2, the effective VAT to consumption ratios do not vary much over all deciles in Korea and Japan. They are almost flat. The decile distribution of effective VAT to consumption is not affected by VAT exemptions as much as that of effective VAT to income. 
Figure 2. Distribution of VAT Effective Rates by Gross Income Decile in Korea and Japan, 2014
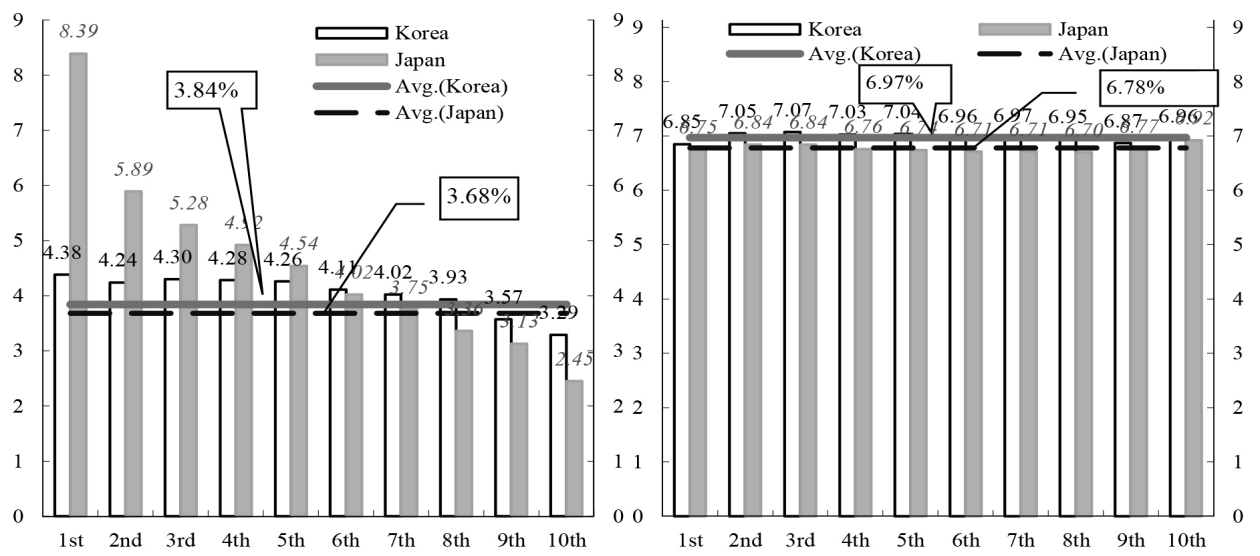

Note: All figures are based on the author's calculations, which are derived from the HIES for Korea and NSFIE for Japan.

\section{Hypothetical Changes in VAT Exemption Systems}

Both Korea and Japan are looking for ways to fiscally consolidate in order to finance increasing welfare expenditure, and in the case of Korea, to cover reunification costs, and in case of Japan, to cope with rapidly growing debt to GDP ratio. The VAT is a key potential revenue source. Experts often recommend a rate increase in both countries. However, the effect of a higher rate on revenue could be weak in Korea, because the scope of its VAT exemptions is too large. A reduction in the number of exempt goods and services could help lower the level of the VAT rate increase required to meet the country's needs without entailing a sacrifice in additional revenue. The regressivity of the VAT burden in Japan largely owes to the fact that so few items and services are VAT exempt. Expanding the number of exempt items and services could ease the resistance against the planned rate increase. Swapping out Korea's and Japan's VAT exemption systems may offer clues as to how to mitigate the negative effects of the VAT and thereby generate more revenue from it. Figure 3 illustrates the simulation results for both countries. The piecewise linear lines denote the actual and hypothetical effective VAT to income ratios by income decile.

The hypothetical application of the Japanese exemption system to Korea results in an escalation of effective rates: it shifts the effective rate curve up, resulting in increased revenue reflected in increased average effective VAT rates. The changes are not proportional but asymmetrical, that is, the lower-income deciles are affected more heavily. The increments to effective rates are larger for lower -income deciles, 
implying that the hypothetical changes in the scope of exemptions increases the regressivity of the VAT burdens in Korea.

The hypothetical application of the Korean exemption system to Japan reduces the effective rates for all income deciles. As shown in the histogram in the right side of figure 3, effective VAT rates decline more for lower-income deciles. This certainly curtails the regressivity of the VAT burden in Japan, implying that one of the undesirable effects of a VAT rate increase can be alleviated by widening the scope of exemptions.

Figure 3. VAT Effective Rates by Income Decile in Swapped-Out Exemption Systems (in \%[left X-axis], \%p[right X-axis])

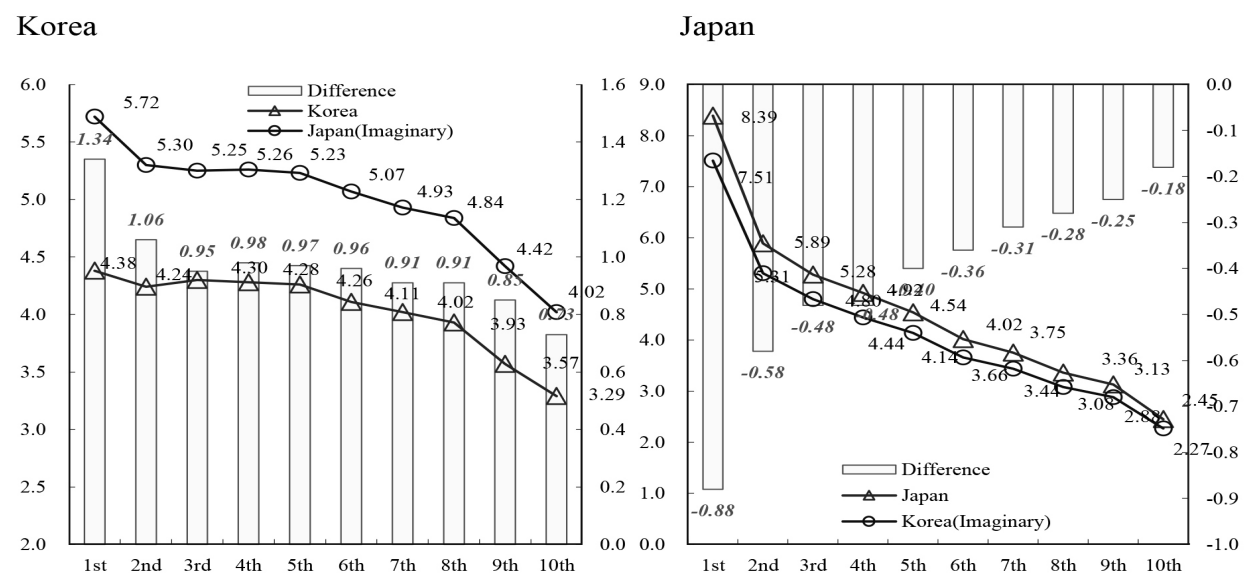

Note: All figures are based on author's own calculations, which are derived from the HIES for Korea and NSFIE for Japan.

\section{The Korean Case}

\section{Distributions of Income, Consumption, and VAT Burdens}

Table 3 shows the decile distributions of income, consumption, and nominal/ effective VAT burdens. The average annual gross income (GY) is 48.1 million per household in 2014. Of this, 26.5 million is the average annual household consumption, and therefore the APC is 0.552 . The average nominal VAT burden is \#1.540 million per household, which is $3.20 \%$ of GY and $5.80 \%$ of average annual household consumption.

Only output VAT is exempt. That is, input VAT is taxable. Therefore, the effec- 
tive VAT burden is generally not zero even for VAT-exempt items. Effective VAT rates are generally higher than $0 \%$ for exempt goods and the nominal rate of $10 \%$ for taxable goods in Korea. The difference between them is due to cascading effects from the undeducted input VAT embedded in VAT-exempt sectors. Cascading effects are generally greater in exempt sectors than in taxable ones. The effective burden induced by cascading effects is relatively greater, particularly for necessities and thus for lower-income deciles, under the Korean VAT exemption system. Table 3 illustrates this for decile distributions of nominal and effective VAT burdens under the Korean VAT exemption system. The ratio of the 10th decile to the 1st decile is 9.54 for nominal burdens, decreasing to 8.08 for effective burdens including cascading effects. This is mainly because the concealed effective burden, particularly for VAT-exempt necessities, is highly concentrated in low-income deciles. Note also that the ratio of the 10th to the 1st decile, both nominal (9.54) and effective (8.08), is smaller than that of income (10.76). This implies that the VAT burden is regressive with respect to income.

Table 3. Distribution of Household Income, Consumption, and VAT Burdens in Korea (2014)

(in thousand \#)

\begin{tabular}{l|c|c|c|c|c|c|c|c|c|c|c|c|c}
\hline & $\begin{array}{c}\text { Exemption } \\
\text { System }\end{array}$ & $\begin{array}{c}\text { 1st } \\
(\mathbf{A})\end{array}$ & 2nd & 3rd & 4th & 5th & 6th & 7th & 8th & 9th & $\begin{array}{c}\text { 10th } \\
\text { (B) }\end{array}$ & Average & B/A \\
\hline $\begin{array}{l}\text { Gross } \\
\text { Income }\end{array}$ & & 10,456 & 18,383 & 25,769 & 32,866 & 39,752 & 46,557 & 54,083 & 63,508 & 77,086 & 112,455 & 48,088 & 10.76 \\
\hline Consumption & & 6,690 & 11,053 & 15,650 & 20,011 & 24,048 & 27,521 & 31,173 & 35,920 & 40,107 & 53,180 & 26,534 & 7.95 \\
\hline APC & & 0.640 & 0.601 & 0.607 & 0.609 & 0.605 & 0.591 & 0.576 & 0.566 & 0.520 & 0.473 & 0.552 & 0.74 \\
\hline \multirow{2}{*}{$\begin{array}{l}\text { Nominal } \\
\text { VAT Rates }\end{array}$} & $\begin{array}{c}\text { Japanese } \\
\text { (Hypothetical) }\end{array}$ & 491 & 595 & 881 & 1,128 & 1,395 & 1,602 & 1,833 & 2,123 & 2,352 & 3,158 & 1,540 & 9.54 \\
\hline \multirow{2}{*}{$\begin{array}{l}\text { Effective } \\
\text { VAT Rates }\end{array}$} & \begin{tabular}{c} 
Korean \\
\cline { 2 - 13 } \\
Jypanese
\end{tabular} & 458 & 779 & 1,169 & 1,516 & 1,855 & 2,133 & 2,425 & 2,830 & 3,150 & 4,207 & 2,059 & 8.57 \\
\hline
\end{tabular}

Notes: All figures are based on the author's own calculations, which are derived from the HIES for 2014. Effective VAT burdens have been estimated based on the scope of VAT exemptions under the 2014 Korean VAT system and under a hypothetical VAT system using the scope of exemptions under the Japanese VAT system. Effective VAT rates by sector are estimated through $\mathrm{IO}$ analyses.

\section{Effects of VAT Exemptions: A Simulation Analysis of the Application of the Japanese VAT System}

The lower half of table 3 shows the results of applying the Japanese VAT exemption system to Korea. In this scenario, the average nominal VAT burden is 2.059 
million per household, which is $33.7 \%$ greater than the current average nominal burden (\$1.540 million).

The aforementioned results are for nominal VAT burdens. However, not all of the effects of VAT exemptions are directly observable because part of the VAT burden is hidden. This hidden burden can be identified through a counterfactual analysis or simulation by replacing the Korean VAT exemption system with a system with no exemptions or a system with few exemptions, like that of Japan. Tables 3 and 4 show the simulation results. Effective VAT burdens in this scenario increase more slowly in upper-income deciles than in lower deciles. More specifically, the ratio of the VAT burden between the 10th and 1st deciles decreases from 8.57 to 7.56 . This is because the scope of exemptions under the Japanese system is much narrower.

The effects of VAT exemptions can be viewed in terms of effective rates measured by the ratio of VAT burdens to income or consumption. Table 4 reports the results under the current Korean exemption system as well as under the hypothetical case in which the Japanese VAT exemption system is applied to Korea. Simulations are conducted under a hypothetical scenario in which the population structure is aged as much as in Japan. The lower half of table 4 shows the simulation results.

The first two rows of table 4 show a comparison between nominal VAT to income ratios in the Korean and Japanese VAT exemption systems. The total average ratio is higher in the hypothetical scenario in which the Japanese exemption system is applied to Korea. The difference between them is $1.08 \%$ p (=4.28\%-3.20\%), as shown in the last column. Differences in VAT to income ratios under the two systems in the middle income deciles between the 3rd and 8th deciles are about $1.1 \% \mathrm{p}$ and similar across these deciles. These differences are almost the same as the total average difference. However, differences in ratios are larger in the lowest two deciles than in the others. By contrast, the difference is smaller in the 10th decile $(0.93 \% \mathrm{p}=3.74 \%-2.81 \%)$ than in the others.

The third and fourth rows of the table show a comparison between effective VAT to income ratios. The total average difference between the Korean and Japanese exemption systems is $0.89 \% \mathrm{p}(=4.73 \%-3.84 \%)$, as shown in the last column. This is slightly smaller than that for the nominal ratio $(1.08 \% \mathrm{p})$.

Noteworthy is that decile distribution patterns of scale differences between the Korean and Japanese VAT exemption systems are reversed with respect to nominal and effective ratios. Unlike in the case of the Korean exemption system, differences are small in lower deciles and large in upper deciles under the hypothetical Japanese exemption system. These differences in distributional patterns are mainly due to cascading effects distributed asymmetrically over deciles. Lower-income households are more likely to rely on VAT-exempt necessities than higher-income ones. The dis- 
tribution of hidden VAT burdens from cascading effects depends heavily on that of the consumption of necessities. Therefore, the distributional patterns of nominal burdens are very different from that of effective burdens.

VAT to consumption ratios can be explained similarly.

Table 4. Ratios of VAT Burdens to Income and Consumption in Korea, 2014 (in \%)

\begin{tabular}{|c|c|c|c|c|c|c|c|c|c|c|c|c|c|c|}
\hline & Base & $\begin{array}{l}\text { Nominal/ } \\
\text { Effective }\end{array}$ & $\begin{array}{c}\text { Exemption } \\
\text { System }\end{array}$ & 1st & 2nd & 3rd & 4th & 5 th & 6th & 7th & 8th & 9th & 10th & Average \\
\hline \multirow{9}{*}{$\begin{array}{l}\text { Unaged } \\
\text { Population } \\
\text { with the } \\
\text { Korean } \\
\text { Sample } \\
\text { Weight }\end{array}$} & \multirow{4}{*}{ Income } & \multirow{2}{*}{ Nominal } & Korean & 3.17 & 3.24 & 3.42 & 3.43 & 3.51 & 3.44 & 3.39 & 3.34 & 3.05 & 2.81 & 3.20 \\
\hline & & & Japanese & 4.70 & 4.43 & 4.54 & 4.61 & 4.67 & 4.58 & 4.48 & 4.46 & 4.09 & 3.74 & 4.28 \\
\hline & & \multirow{2}{*}{ Effective } & Korean & 4.38 & 4.24 & 4.30 & 4.28 & 4.26 & 4.11 & 4.02 & 3.93 & 3.57 & 3.29 & 3.84 \\
\hline & & & Japanese & 5.72 & 5.30 & 5.25 & 5.26 & 5.23 & 5.07 & 4.93 & 4.84 & 4.42 & 4.02 & 4.73 \\
\hline & \multirow{4}{*}{ Consumption } & \multirow{2}{*}{ Nominal } & Korean & 4.95 & 5.38 & 5.63 & 5.64 & 5.80 & 5.82 & 5.88 & 5.91 & 5.86 & 5.94 & 5.80 \\
\hline & & & Japanese & 7.34 & 7.37 & 7.47 & 7.58 & 7.71 & 7.75 & 7.78 & 7.88 & 7.85 & 7.91 & 7.76 \\
\hline & & \multirow{2}{*}{ Effective } & Korea & 6.85 & 7.05 & 7.07 & 7.03 & 7.04 & 6.96 & 6.97 & 6.95 & 6.87 & 6.96 & 6.97 \\
\hline & & & Japanese & 8.94 & 8.82 & 8.65 & 8.63 & 8.64 & 8.58 & 8.55 & 8.55 & 8.50 & 8.50 & 8.58 \\
\hline & & $\begin{array}{l}\text { Nominal/ } \\
\text { Effective }\end{array}$ & $\begin{array}{l}\text { Exemption } \\
\text { System }\end{array}$ & 1st & 2nd & 3rd & 4th & 5 th & 6th & 7th & 8th & 9th & 10th & Average \\
\hline \multirow{8}{*}{$\begin{array}{l}\text { Hypothetical } \\
\text { Aged } \\
\text { Population } \\
\text { with the } \\
\text { Japanese } \\
\text { Sample } \\
\text { Weight) }\end{array}$} & \multirow{4}{*}{ Income } & \multirow{2}{*}{ Nominal } & Korean & 3.42 & 3.02 & 3.11 & 2.94 & 3.06 & 3.26 & 3.13 & 3.31 & 3.00 & 2.78 & 3.04 \\
\hline & & & Japanese & 4.91 & 4.21 & 4.23 & 4.04 & 4.10 & 4.26 & 4.13 & 4.32 & 3.92 & 3.61 & 4.03 \\
\hline & & \multirow{2}{*}{ Effective } & Korean & 4.64 & 3.99 & 4.03 & 3.81 & 3.69 & 3.86 & 3.77 & 3.84 & 3.45 & 3.20 & 3.64 \\
\hline & & & Japanese & 5.93 & 5.06 & 5.00 & 4.73 & 4.62 & 4.73 & 4.65 & 4.67 & 4.22 & 3.87 & 4.47 \\
\hline & \multirow{4}{*}{ Consumption } & \multirow{2}{*}{ Nominal } & Korean & 5.11 & 5.24 & 5.39 & 5.37 & 5.67 & 5.86 & 5.78 & 6.04 & 6.00 & 6.10 & 5.82 \\
\hline & & & Japanese & 7.34 & 7.31 & 7.34 & 7.38 & 7.60 & 7.67 & 7.63 & 7.88 & 7.85 & 7.94 & 7.71 \\
\hline & & \multirow{2}{*}{ Effective } & Korean & 6.93 & 6.93 & 6.98 & 6.96 & 6.85 & 6.95 & 6.97 & 7.00 & 6.90 & 7.04 & 6.96 \\
\hline & & & Japanese & 8.86 & 8.78 & 8.66 & 8.64 & 8.56 & 8.51 & 8.59 & 8.52 & 8.45 & 8.50 & 8.55 \\
\hline
\end{tabular}

Notes: "Unaged population" refers to the current data set from the HIES as of 2014 and "aged population" refers to a hypothetical data set in which the Korean sample weight by age group has been replaced with that of the Japanese NSFIE for 2014.

Note that Japan is more aged than Korea in terms of population age structure. I analyze the effects of population aging on VAT incidence by applying the Japanese sample weight by age group to the Korean sample of the HIES. The lower half of table 4 shows the simulation results. Population aging implies an increasing share of older individuals who are likely to consume necessities relatively more than younger ones. Since most necessities are exempt from the VAT in Korea, this implies that a more aged society is likely to bear less of the VAT burden. The Japanese population is more aged than the Korean one. This results in a lower VAT to income ratio, as shown in figure 4. The lowest VAT to income ratios are found in elderly households aged 65 or over, implying that aging households are more likely to have redistributive effects in an aging society such as Japan than in a younger one such as Korea for given VAT exemptions for necessities.

This is well reflected in table 4. The VAT to income ratios in the last column are lower under the hypothetical aged population than under the actual population. For 
example, $3.20 \%$ of the average nominal VAT rate compared with income in the first row for the actual population decreases to $3.04 \%$ for the hypothetical aged one. These phenomena are consistent across all deciles except for the bottom decile. The VAT to income ratio is higher for the hypothetical aged population than for the actual one in the first decile, unlike in the others. The nominal VAT burden under the actual population is $3.17 \%$ but jumps up to $3.42 \%$ under the hypothetical population. This is because the bottom decile is most severely affected by the aging process. There are two competing effects of aging. Aging is likely to increase the APC, particularly in the 1 st decile, and thus to increase the VAT to income ratio sharply. The increased share of the aging population is then likely to shift it downward because older individuals are likely to consume VAT-exempt items relatively more than younger ones. In Korea, the former effect outweighs the latter only in the bottom decile, whereas the latter effect outweighs the former in other deciles.

Figure 4. Distribution of VAT to Income Ratios by Household Head Age in Korea (in \%)

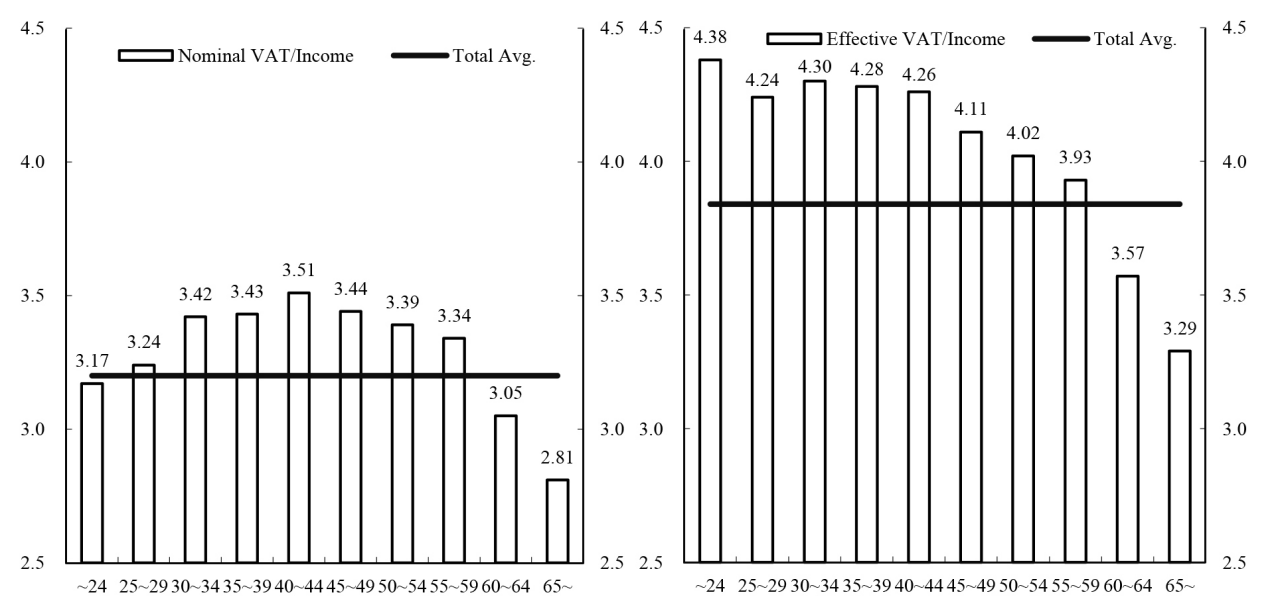

Note: All figures are nominal or effective VAT rates estimated by the author, which are derived from the HIES for 2014. Total average VAT ratios to income are $3.20 \%$ and $3.84 \%$, respectively

\section{The Japanese Case}

\section{Distributions of Income, Consumption, and VAT Burdens}

Table 5 reports Japan's decile distributions of income, consumption, and VAT burdens for 2014. The mean annual gross income and consumption per household 
are $¥ 5.531$ million and $¥ 2.895$ million, respectively. The APC is 0.543 , which is slightly lower than that of Korea (0.552). The relative gap in gross income between the 10th and 1st deciles is slightly larger in Japan (11.90 in table 5) than in Korea (10.76 in table 3). The relative consumption gap between the top and bottom deciles is, by contrast, merely 3.39 .

The APC of the bottom decile exceeds 1, implying that the average household balance is negative and thus that there is a deficit. This can be explained in part by reference to aging. As reported in table A.4, older households aged 65 or over account for $62.66 \%(=16.61 \%+16.63 \%+29.42 \%)$ of all households in the bottom decile in Japan, which is far higher than the total average share of $22.67 \%$ $(=7.62 \%+7.22 \%+7.83 \%)$ for the total sample.14 An alternative interpretation is that the APC of the 1st decile exceeds 1 because most of its consumption depends on permanent income, which is generally greater than current income for older individuals, in line with the life-cycle hypothesis. In other words, their consumption depends more on their asset-based income than on their current income, and this is likely to contribute to a more regressive VAT incidence measured by current income than by permanent income, which is not directly observed here.

The decile distribution of nominal VAT burdens in Japan is similar to that of consumption except for scale differences. This is not only because the scope of VAT exemptions is narrow but also because Japan has a single-rate VAT system. Therefore, the relative VAT gap between deciles is not that different from that of consumption. It is merely 3.46 between the top and bottom deciles (reported in the fourth row, last column, of table 5), which is slightly higher than that of consumption (3.39) (second row, last column). The distribution of effective VAT burdens is also similar to that of nominal burdens except for the absolute scale. The latter is slightly larger than the former because of concealed VAT burdens from cascading effects. As a result, VAT incidence in Japan is roughly proportional to consumption. However, it is regressive with respect to income, implying negative income redistribution. Therefore, the regressivity of VAT incidence comes mainly from differences between permanent and current income distributions, which is generally observed in aged countries.

14. $76.79 \%$ of households are elderly (that is, headed by a person age 65 or older) in the 1 st decile in Korea, whereas across the sample as a whole only $24.18 \%$ are. 
Table 5. Distribution of Annual Income, Consumption, and VAT Burdens in Japan, 2014

(in thousand $¥$ )

\begin{tabular}{|c|c|c|c|c|c|c|c|c|c|c|c|c|c|}
\hline & $\begin{array}{l}\text { Exemption } \\
\text { System }\end{array}$ & $\begin{array}{l}\text { 1st } \\
\text { (A) }\end{array}$ & 2nd & 3 rd & 4th & 5th & 6th & 7th & 8th & 9th & $\begin{array}{l}\text { 10th } \\
\text { (B) }\end{array}$ & Average & $\mathrm{B} / \mathrm{A}$ \\
\hline Gross Income & & 1,162 & 2,059 & 2,753 & 3,362 & 4,031 & 4,812 & 5,747 & 6,945 & 8,612 & 13,823 & 5,331 & 11.90 \\
\hline Consumption & & 1,444 & 1,772 & 2,125 & 2,445 & 2,714 & 2,882 & 3,216 & 3,480 & 3,977 & 4,895 & 2,895 & 3.39 \\
\hline APC & & 1.243 & 0.861 & 0.772 & 0.727 & 0.673 & 0.599 & 0.56 & 0.501 & 0.462 & 0.354 & 0.543 & - \\
\hline \multirow{2}{*}{$\begin{array}{l}\text { Nominal } \\
\text { VAT Rates }\end{array}$} & Japanese & 85 & 106 & 130 & 146 & 164 & 173 & 194 & 208 & 237 & 294 & 174 & 3.46 \\
\hline & $\begin{array}{c}\text { Korean } \\
\text { (Hypothetical) }\end{array}$ & 68 & 85 & 105 & 118 & 134 & 142 & 160 & 172 & 195 & 244 & 142 & 3.59 \\
\hline \multirow{2}{*}{$\begin{array}{l}\text { Effective } \\
\text { VAT Rates }\end{array}$} & Japanese & 97 & 121 & 145 & 165 & 183 & 193 & 216 & 233 & 269 & 338 & 196 & 3.48 \\
\hline & $\begin{array}{c}\text { Korean } \\
\text { (hypothetical) }\end{array}$ & 87 & 109 & 132 & 149 & 167 & 176 & 198 & 214 & 248 & 313 & 179 & 3.60 \\
\hline
\end{tabular}

Notes: All figures are based on the author's own calculations, which are derived from the 2014 NSFIE

\section{Effects of VAT Exemptions: A Simulation Analysis of the Application of the Korean VAT System}

The mean nominal VAT burden is smaller in Japan if the Korean VAT exemption system is applied. There is a $18.4 \%$ decrease in the nominal VAT burden ( $¥ 174$ thousand $\rightarrow$ $¥ 142$ thousand per household; see the fourth and third rows from the bottom in table 5).

The regressivity of VAT incidence can be easily seen by comparing its ratio in the top and bottom deciles, although that ratio ignores the distributional characteristics of VAT burdens in in-between deciles. In Japan, the ratios of nominal VAT burdens in the 1st and 10th deciles are 3.46 under the Japanese VAT exemption system and 3.59 under the hypothetically applied Korean VAT exemption system, as shown in the fourth and fifth rows of table 5. The VAT ratios of these two deciles are greater than the APC (3.39). This implies that nominal VAT incidence is regressive with respect income but slightly progressive with respect to consumption in terms of the decile ratio in Japan. Therefore, although VAT incidence is regressive with respect to income, VAT exemptions may have a positive distributional effect by mitigating the regressive redistributive effect, a mitigation suggested by the fact that the VAT ratio of 10 th to 1 st decile outweighs that of consumption.

Nominal and effective VAT burdens do not usually coincide because of VAT exemptions. As shown in table 5, the mean difference between nominal and effective burdens is larger at $¥ 37$ (=179-142) thousand per household under the hypothetical Korean VAT exemption system than at $¥ 22$ (=196-174) thousand under the actual Japanese VAT exemption system. The expansion of VAT exemptions directly reduces the nominal output VAT through a decreased VAT base but increases the 
undeducted input VAT through increased cascading effects. These effects collide. The former generally dominates to the extent that the VAT-taxable scope is greater than the exemption scope.

Decile distributions of VAT to income and VAT to consumption ratios, both of which are reported in table 6, verifies the regressivity of VAT incidence. The law of diminishing MPC is clearly apparent in Japan. More specifically, the highest nominal VAT to income ratio is observed in the bottom decile, and the ratio decreases continuously to the top decile with no exceptions, as shown in the first row of the table and by its effective ratio in the third row. The hypothetical application of the Korean VAT exemption system does not affect these patterns of continuously decreasing MPC and VAT incidence across deciles. However, these patterns are reversed in the case of the VAT to consumption ratio. As briefly noted, the consumption gap is smaller than the VAT gap between the top and bottom deciles. With no VAT exemptions, VAT incidence measured by the VAT to consumption ratio is the same across income deciles. The VAT to consumption ratio is likely to increase in income decile not only for nominal burdens but also for effective burdens, as shown in the lower half of table 6. This implies that increasing the scope of VAT exemptions in Japan could help alleviate the negative effect of the VAT on income distribution. If the Japanese VAT exemption system is hypothetically replaced with the Korean system, then, the absolute difference in the VAT to consumption ratio between the 10th and 1st deciles increases slightly from $0.08 \% \mathrm{p}(6.00 \%$ of the 10th decile $-5.92 \%$ of the 1 st decile in the first row of the lower half of table 6) to $0.26 \%$ p ( $4.98 \%-4.72 \%$ in the next row) both for nominal burden. This implies that VAT exemptions, particularly for necessities, can help mitigate the effect of negative income redistribution by the VAT.

Table 6. Distribution of VAT Ratios for Income and Consumption in Japan, 2014 (in \%)

\begin{tabular}{|c|c|c|c|c|c|c|c|c|c|c|c|c|}
\hline VAT/Income & $\begin{array}{l}\text { Exemption } \\
\text { System }\end{array}$ & 1st & 2nd & 3rd & 4th & 5th & 6th & 7th & 8th & 9th & 10th & Average \\
\hline \multirow{2}{*}{$\begin{array}{l}\text { Nominal } \\
\text { VAT Rates }\end{array}$} & Japanese & 7.35 & 5.14 & 4.73 & 4.34 & 4.06 & 3.60 & 3.37 & 2.99 & 2.75 & 2.12 & 3.26 \\
\hline & $\begin{array}{c}\text { Korean } \\
\text { (Hypothetical) }\end{array}$ & 5.87 & 4.14 & 3.83 & 3.51 & 3.31 & 2.96 & 2.79 & 2.48 & 2.27 & 1.76 & 2.67 \\
\hline \multirow{2}{*}{$\begin{array}{l}\text { Effective } \\
\text { VAT Rates }\end{array}$} & Japanese & 8.39 & 5.89 & 5.28 & 4.92 & 4.54 & 4.02 & 3.75 & 3.36 & 3.13 & 2.45 & 3.68 \\
\hline & $\begin{array}{c}\text { Korean } \\
\text { (Hypothetical) }\end{array}$ & 7.51 & 5.31 & 4.80 & 4.44 & 4.14 & 3.66 & 3.44 & 3.08 & 2.88 & 2.27 & 3.37 \\
\hline $\begin{array}{l}\text { VAT/ } \\
\text { Consumption }\end{array}$ & $\begin{array}{l}\text { Exemption } \\
\text { System }\end{array}$ & $1^{\text {st }}$ & 2nd & $3 r d$ & 4th & 5th & 6th & 7th & 8th & 9th & 10th & Avg. \\
\hline
\end{tabular}




\begin{tabular}{l|c|c|c|c|c|c|c|c|c|c|c|c}
\hline \multirow{2}{*}{$\begin{array}{l}\text { Nominal } \\
\text { VAT Rates }\end{array}$} & Japanese & 5.92 & 5.98 & 6.12 & 5.96 & 6.03 & 6.02 & 6.02 & 5.97 & 5.96 & 6.00 & 6.00 \\
\cline { 2 - 11 } & $\begin{array}{c}\text { Korean } \\
\text { (Hypothetical) }\end{array}$ & 4.72 & 4.81 & 4.96 & 4.82 & 4.92 & 4.94 & 4.98 & 4.94 & 4.91 & 4.98 & 4.92 \\
\hline $\begin{array}{l}\text { Effective } \\
\text { VAT Rates }\end{array}$ & $\begin{array}{c}\text { Japanese } \\
\text { Korean }\end{array}$ & 6.75 & 6.84 & 6.84 & 6.76 & 6.74 & 6.71 & 6.71 & 6.70 & 6.77 & 6.92 & 6.78 \\
\hline
\end{tabular}

Note: All figures are based on the author's own calculation, which are derived from the 2014 NSFIE by gross income decile.

An increase in the VAT rate in Japan increases regressive VAT burdens through an increase in the effect of negative income redistribution. A complementary measure is to allow for an increase in VAT exemptions, particularly for necessities, even if that would entail some revenue loss. The following section discusses the distributive effects of the VAT in greater detail.

\section{Effects of VAT Exemptions on Income Redistribution under Population Aging}

The effects of VAT on income redistribution are estimated and reported for Korea and Japan in tables 7 and 8, respectively. The effects are measured in terms of percentage changes in Gini coefficients between gross income and post-VAT income. In addition, the effects of population aging on income redistribution are estimated by switching the sample weight by age group between the two countries.

\section{Korea}

The Gini coefficient in 2014 rose by $0.30 \%$ from 0.33574 to 0.33676 in Korea as a result of the imposition of the nominal VAT, as shown in the second row of table 7. With hidden VAT burdens from cascading effects, the negative effect on income redistribution increases to $0.57 \%$. That is, the Gini coefficient for post-VAT income increases further to 0.33765 , as shown in the fourth row.

Hypothetically narrowing the VAT exemption scope increases the nominal VAT burden, as shown in table 3 ( $\$ 1,540$ thousand $\rightarrow$ 2,059 thousand per household), and the Gini coefficient for post-VAT income, implying that the negative effect on income redistribution increases from $0.30 \%$ to $0.46 \%$.

If this effect is measured by the effective burden instead of the nominal burden, then it increases even more. The percentage change in the Gini coefficient for post-VAT income increases from $0.57 \%$ to $0.74 \%$, as shown in the fourth and fifth rows of table 7 .

Changes in the VAT exemption scope thus induce asymmetric changes in output 
and input VAT burdens. The contraction of the range of VAT exemptions certainly increases the nominal output of VAT proportionally across deciles, which is regressive with respect to income. However, it also increases the deduction of the input VAT asymmetrically across deciles such that its distribution becomes increasingly skewed toward lower income deciles, which are more likely to rely on necessities. In turn, the fact that members of lower-income deciles rely more on necessities is likely to reduce VAT burdens of households in lower-income deciles. The final effects depend on the relative strength between these two. In the hypothetical swapping out of VAT exemption systems, the former outweighs the latter in terms of the absolute value. Therefore, the combined effect reinforces the negative effects of the VAT on income redistribution in Korea to the extent that the cascading effect is reduced.

It can be tentatively concluded that Korea can increase its VAT revenue by narrowing the scope of VAT exemptions only at the expense of an increase in the negative effect of nominal VAT incidence. This would perhaps cause some tax resistance among Korean taxpayers. Because real effects are not directly observed, a policy change to narrow the scope of VAT exemptions is not likely to be supported, although the true redistributive effect can be realized by reducing the negative redistributive effect.

Although the Korea VAT system is single rate, VAT incidence is regressive not only because of the diminishing MPC but also because of asymmetric consumption patterns for necessities across age groups. Without any change in the VAT structure, the distributional effects of VAT exemptions can change over time, mainly because of population aging. This effect can be estimated through simulations based on the hypothetical application of the Japanese sample weight in the NSFIE by age group to the Korean data set of the HIES. The lower half of table 7 reports the simulation results. If the population structure of the Korean HIES is aged in accordance with that of Japan, then income inequality may increase. The GY Gini coefficient remains more or less the same; it increases only slightly by $0.06 \%$ from 0.33574 to 0.33594 , which implies that population aging may increase income inequality through an increase in the population share of older individuals, who are often retirees with little market income. However, the increase is not that large.

Also note that the regressivity of VAT incidence may be partly mitigated by heavier reliance on VAT-exempt necessities, particularly among older individuals, because exemptions for these items can reduce the negative effect of VAT on income distribution. This phenomenon is evident in simulations for population aging. The Gini coefficient for post-VAT income increases slightly from 0.33594 to 0.33641 , as shown in the second row of the lower half of table 7. This may be because the effect of VAT exemptions on necessities outweighs the overall regressive effect of VAT incidence when there is an increase in the size of an elderly population that depends 
more heavily on necessities. This pattern disappears when the scope of VAT exemptions is narrowed to that in Japan.

In sum, the results suggest that population aging increases income inequality but can also reduce the regressive effect of VAT incidence as long as the scope of VAT exemptions is sufficiently wide.

Table 7. Effects of the VAT on Income Redistribution in Korea, 2014

\begin{tabular}{|c|c|c|c|c|}
\hline Original Sample & $\begin{array}{c}\text { Nominal/ } \\
\text { Effective VAT } \\
\text { Rates }\end{array}$ & $\begin{array}{l}\text { Exemption } \\
\text { System }\end{array}$ & $\begin{array}{c}\text { Gini } \\
\text { coefficient }\end{array}$ & $\begin{array}{c}\% \text { change } \\
\text { in Gini }\end{array}$ \\
\hline GY & & & 0.33574 & \\
\hline \multirow{4}{*}{ GY-VAT } & \multirow[b]{2}{*}{ Nominal } & Korean & 0.33676 & +0.30 \\
\hline & & $\begin{array}{c}\text { Japanese } \\
\text { (Hypothetical) }\end{array}$ & 0.33728 & +0.46 \\
\hline & \multirow[b]{2}{*}{ Effective } & Korean & 0.33765 & +0.57 \\
\hline & & $\begin{array}{c}\text { Japanese } \\
\text { (Hypothetical) }\end{array}$ & 0.33824 & +0.74 \\
\hline $\begin{array}{l}\text { Aged Sample Replaced with } \\
\text { the Japanese Sample Weight } \\
\text { by Age Group }\end{array}$ & $\begin{array}{l}\text { Nominal/ } \\
\text { Effective }\end{array}$ & $\begin{array}{l}\text { Exemption } \\
\text { System }\end{array}$ & $\begin{array}{c}\text { Gini } \\
\text { coefficient }\end{array}$ & $\begin{array}{l}\% \text { change } \\
\text { in Gini }\end{array}$ \\
\hline GY & & & 0.33594 & \\
\hline \multirow{4}{*}{ GY-VAT } & \multirow[b]{2}{*}{ Nominal } & Korean & 0.33641 & +0.14 \\
\hline & & $\begin{array}{c}\text { Japanese } \\
\text { (Hypothetical) }\end{array}$ & 0.33704 & +0.33 \\
\hline & \multirow[b]{2}{*}{ Effective } & Korean & 0.33739 & +0.43 \\
\hline & & $\begin{array}{c}\text { Japanese } \\
\text { (Hypothetical) }\end{array}$ & 0.33806 & +0.63 \\
\hline
\end{tabular}

Notes: 1. All figures are based on the author's own calculation, which are derived from the 2014 NSFIE.

2. The aged sample is identical to the original one except for the sample weight, which is replaced with that of the Japanese NFSIE by age group.

3. A positive (negative) value of the percentage change in the Gini coefficient implies a negative (or positive) effect on income redistribution because the Gini coefficient for post-VAT income increases (or decreases).

\section{Japan}

Because VAT incidence is also regressive in Japan, it likewise has a negative effect on income distribution. As reported in table 8, the percentage change in the Gini coefficient for nominal VAT burdens induced by the imposition of the VAT is quite high at $1.54 \%(0.35402 \rightarrow 0.35948)$. This is about 5 times that for Korea. 
Given Japan's VAT rate ( $8 \%$ in 2014) in comparison to that in Korea (10\%), the negative redistributive effect is sizable in Japan. The hypothetical expansion of VAT exemptions based on the Korean exemption system reduces the redistributive effect from $1.54 \%$ p to $1.21 \%$ p at the expense of revenue. The redistributive effect of effective VAT burdens exceeds that of nominal burdens. The change in the redistributive effect that arise from the broadening of the scope of VAT exemptions is smaller for effective burdens than for nominal burdens: $0.20 \%$ p (=1.73\%p-1.53\%p) vs. $0.33 \%$ p $(=1.54 \%$ p- $1.21 \% \mathrm{p})$, respectively, as shown in the last column of table 8 .

The planned increase in the VAT rate from 5\% through $8 \%$ to $10 \%$ in Japan is likely to increase the VAT burden sharply through the inflation of the negative effect on income redistribution. Although regressive VAT burdens are generally not considered burdensome before a rate increase, they may be considered as such when the VAT rate doubles $(5 \% \rightarrow 8 \% \rightarrow 10 \%)$. An increasing number of consumers are likely to face an increase in regressive VAT burdens in addition to induced inflation. Therefore, the issue of vertical equity may become a topic of increasing concern. One way to prevent or mitigate strong VAT resistance from this rate increase would be to expand the scope of VAT exemptions. This may mitigate the increment in the Gini coefficient induced by the increase in the VAT rate. If the VAT rate ends up increasing from $8 \%$ to $10 \%$, then the negative effect in income redistribution would increase additionally by $0.43 \%$ p (i.e., an additional $25 \%$ increase in effective VAT burdens induced by a rate increase from $8 \%$ to $10 \%$; that is, $0.43 \%$ p is a quarter of $1.73 \%$ p). At the same time, there would be an increase in revenue roughly as large as the current level.

If the scope of VAT exemptions is broadened in line with the Korean VAT exemption system, then Japan loses about 8.7\% in revenue (¥196 thousand $\rightarrow ¥ 179$ thousand per household in terms of effective VAT burdens, as shown in the column reporting averages, that is, the second column from the right), as reported in the lower half of table 5. However, it also reduces the negative effect on income redistribution by about $0.20 \% \mathrm{p}(1.73 \% \mathrm{p} \rightarrow 1.53 \% \mathrm{p}$ in terms of effective VAT burdens), as shown in table 8 . In fact, there is a tradeoff between revenue and redistribution. Therefore, a policy option that should be considered when increasing the VAT rate is broadening the scope of VAT exemptions as means of addressing an increase in inequitable redistribution from increased VAT burdens.

What faces Japan if its population structure is less aged? According to simulation results (table 8), the GY Gini coefficient decreases by $5.1 \%$ from 0.35402 to 0.33581 . This gap likely reflects an aging effect on income inequality. If the Japanese population structure is less aged, then the negative effect of VAT exemptions on income redistribution decreases from $+1.54 \% \mathrm{p}$ to $+1.32 \% \mathrm{p}$, as shown in the second and seventh rows of table 8 . If the scope of VAT exemptions is widened to the Kore- 
an level, then the negative effect decreases to $+1.03 \% \mathrm{p}$. This implies that the general application of the standard single VAT rate with few exemptions, as in the case of the Japanese VAT system, is likely to strengthen allocative efficiency by minimizing any distortion caused by allowing more exemptions at the expense of distributional equity. Unlike in the case of the actual sample population, the expansion of VAT exemptions in the hypothetical unpaged sample increases the negative effects, which may be due to asymmetric changes in concealed VAT burdens from cascading effects through changes in the sample weight across age groups.

Table 8. Effects of the VAT on Income Redistribution in Japan, 2014

\begin{tabular}{|c|c|c|c|c|}
\hline Original sample & $\begin{array}{c}\text { Nominal/ } \\
\text { Effective } \\
\text { VAT RATES }\end{array}$ & $\begin{array}{l}\text { Exemption } \\
\text { System }\end{array}$ & $\begin{array}{c}\text { Gini } \\
\text { coefficient }\end{array}$ & $\begin{array}{c}\% \text { change } \\
\text { in Gini }\end{array}$ \\
\hline GY & & & 0.35402 & \\
\hline \multirow{4}{*}{ GY-VAT } & \multirow[b]{2}{*}{ Nominal } & Japanese & 0.35948 & +1.54 \\
\hline & & $\begin{array}{c}\text { Korean } \\
\text { (Hypothetical) }\end{array}$ & 0.35831 & +1.21 \\
\hline & \multirow[b]{2}{*}{ Effective } & Japanese & 0.36014 & +1.73 \\
\hline & & $\begin{array}{c}\text { Korean } \\
\text { (Hypothetical) }\end{array}$ & 0.35943 & +1.53 \\
\hline $\begin{array}{l}\text { Unaged Sample Replaced } \\
\text { with the Korean Sample } \\
\text { Weight by Age Group }\end{array}$ & $\begin{array}{l}\text { Nominal/ } \\
\text { Effective }\end{array}$ & $\begin{array}{l}\text { Exemption } \\
\text { System }\end{array}$ & $\begin{array}{c}\text { Gini } \\
\text { coefficient }\end{array}$ & $\begin{array}{l}\% \text { change } \\
\text { in Gini }\end{array}$ \\
\hline GY & & & 0.33581 & \\
\hline \multirow{4}{*}{ GY-VAT } & \multirow[b]{2}{*}{ Nominal } & Japanese & 0.34023 & +1.32 \\
\hline & & $\begin{array}{c}\text { Korean } \\
\text { (Hypothetical) }\end{array}$ & 0.33926 & +1.03 \\
\hline & \multirow[b]{2}{*}{ Effective } & Japanese & 0.34112 & +1.58 \\
\hline & & $\begin{array}{c}\text { Korean } \\
\text { (Hypothetical) }\end{array}$ & 0.34108 & +1.57 \\
\hline
\end{tabular}

Notes: 1. All figures are based on the author's own calculations, which are derived from the 2014 NSFIE.

2. The unaged sample is identical to the actual one except for the sample weight, which is replaced with that of the Korean HIES by age group.

3. A positive (negative) value for the percentage change in the Gini coefficient implies a negative (or positive) effect on income redistribution because the Gini coefficient for post-VAT income increases (decreases). 


\section{CONCLUSIONS}

This paper reports the results of IO and counterfactual simulation analyses that I jointly conducted to analyze revenue and distributional impacts of VAT exemptions in Korea and Japan. Korea is a country with a broad range VAT exemptions, whereas Japan has a narrow range of narrow exemptions.

In both countries, VAT incidence is regressive with respect income, and its effect on income redistribution is negative. Korea allows a wide range of VAT exemptions, particularly for necessities, which helps to address regressivity at the expense of revenue. By contrast, Japan allows no VAT exemptions except in several selected sectors, thereby securing allocative efficiency at the expense of redistribution. Paradoxically, the regressivity of VAT incidence in Korea, where the VAT rate is $10 \%$, is less than that in Japan, where the VAT rate is $8 \%$, as of 2014 .

Fiscal consolidation is crucial for revenue generation in both countries. The VAT is most frequently highlighted as a primary source of additional revenue. The estimation results in this paper have several important implications. Korea should reduce the scope of VAT exemptions even in the face of worry over equity before considering an increase in its rate. This is because the anticipated increase in the regressivity of VAT incidence is not large and thus tolerable. More specifically, the negative effect on income redistribution is smaller in Korea than in Japan, although Korea's VAT rate is $10 \%$ (twice that of Japan before the recent rate increase in 2014). An increase in the VAT rate is thus a good option for Korea. Japan should consider broadening the scope of VAT exemptions to address regressive VAT incidence that has already occurred with its rate increases from $5 \%$ to $8 \%$ and that is expected to continue with the planned increase to $10 \%$ in 2019. Although such a change would lead to some revenue loss, it would help mitigate heavier VAT burdens, particularly in low-income deciles and thus minimize the undesirable effects of the VAT rate increase.

\section{REFERENCES}

Arsić, M., \& Altiparmakov, N. 2013. Equity aspects of VAT in emerging European countries: A case study of Serbia. Economic Systems, 37(2): 171-186.

Barrell, R., \& Weale, M. 2009. The economics of a reduction in VAT. Fiscal Studies, 30(1): 17-30.

Caspersen, E., \& Metcalf, G. 1994. Is a value added tax regressive? Annual versus 
lifetime incidence measures. National Tax Journal, 47(4): 731-746.

Creedy, J. 1998. Are consumption taxes regressive? Australian Economic Review, 31(2): 107-116.

Crossley, T. F., Low, H., \& Wakefield, M. 2009. The economics of a temporary VAT cut. Fiscal Studies, 30(1): 3-16.

Decoster, A., Loughrey, J., O’Donoghue, C. \& Verwerft, D. 2010. How Regressive Are Indirect Taxes? A Microsimulation Analysis of Five European Countries. Journal of Policy Analysis and Management, 29(2): 326-350.

Ebrill, L.P., Keen, M., \& Summers, V. P. 2001. The modern VAT. Washington, DC: IMF.

European Commission. 2011. Tax reforms in EU member states 2011. Brussels: Directorate-General for Economic and Financial Affairs. European Commission.

International Tax Dialogue. 2012. The value added tax: Experiences and issues.

Gottfried, P., \& Wiegard, W. 1991. Exemption versus zero rating: A hidden problem of VAT. Journal of Public Economics, 46(3): 307-328.

Liberati, P. 2001. The distributional effects of indirect tax changes in Italy. International Tax and Public Finance, 8(1): 27-51.

Marks, S. V. 2003. The value added tax in Indonesia: The impact of sectoral exemptions on revenue potential and effective tax rates. Jakarta: Bappenas.

Matthews, K., \& Lloyd-Williams, J. 2010. Have VAT rates reached their limit? An empirical note. Applied Economics Letters, 7(2): 111-115.

OECD. 2011. National tax policy developments: Issues for discussion and responses to the 2011 questionnaire. CTPA/CFA/WP2 10, May 5, 2011.

OECD. 2013. Report on preliminary results from the joint WP2/WP9 project on the distributional effects of consumption taxes. CTPA/CFA/WP2 30, November 6 , 2013.

OECD. 2017. Revenue Statistics, 1965-2016.

Pechman, J. A., \& Okner, B. A. 1974. Who bears the tax burden? Washington, DC: Brookings Institution Press.

Sung, M. J. 2013. Estimation of effective VAT rates and effects of exemption on tax revenue and income redistribution. Korean Journal of Taxation Research, 30(3): 189-223.

Sung, M. J., Park, M., Lee, S., \& Park, J. 2012. Medium- and long-term VAT reforms. Research report, Ministry of Strategy and Finance and Korea Institute of Public Finance.

Tamaoka, M. 1994. The regressivity of a value added tax: Tax credit method and subtraction method--a Japanese case. Fiscal Studies, 15(2): 57-73. 


\section{Appendix: Miscellaneous Tables}

Table A. 1. Scope of VAT Exemptions in Korea and Japan

\begin{tabular}{|c|c|c|}
\hline \multirow{2}{*}{ Category } & \multicolumn{2}{|c|}{ Items } \\
\hline & Korea & Japan \\
\hline \multirow{5}{*}{$\begin{array}{l}\text { Basic } \\
\text { Necessities }\end{array}$} & unprocessed food & \\
\hline & water, coal products for household use & \\
\hline & sanitary pads & \\
\hline & $\begin{array}{l}\text { mass transportation (exclusive of taxis, } \\
\text { airplanes, high-speed trains, etc.) }\end{array}$ & \\
\hline & rent & rent \\
\hline \multirow{5}{*}{$\begin{array}{l}\text { Welfare- and } \\
\text { Culture- } \\
\text { Related } \\
\text { Items }\end{array}$} & $\begin{array}{l}\text { medical services and blood (exclusive of } \\
\text { selected cosmetic surgeries) }\end{array}$ & $\begin{array}{l}\text { medical treatment under public } \\
\text { medical insurance law }\end{array}$ \\
\hline & education services & $\begin{array}{l}\text { school tuition and examination } \\
\text { services }\end{array}$ \\
\hline & books, newspapers, magazines, etc. & \\
\hline & arts, nonprofessional sport activities & \\
\hline & museums, etc. & \\
\hline \multirow{3}{*}{$\begin{array}{l}\text { Production } \\
\text { Factors }\end{array}$} & land & sales or leases of land \\
\hline & financial services, insurance premiums & $\begin{array}{l}\text { sales of securities and similar } \\
\text { instruments, monetary transactions } \\
\text { (e.g. loans, guarantees, insurance } \\
\text { premiums, etc.) }\end{array}$ \\
\hline & $\begin{array}{l}\text { services provided by writers, composers, } \\
\text { painters, etc. }\end{array}$ & \\
\hline \multirow{3}{*}{ Other } & stamps & $\begin{array}{l}\text { transfers of postage stamps, } \\
\text { revenue stamps, etc. by the central } \\
\text { and local governments }\end{array}$ \\
\hline & $\begin{array}{l}\text { services provided by religion-related } \\
\text { bodies }\end{array}$ & \\
\hline & $\begin{array}{l}\text { services provided by central and local } \\
\text { governments }\end{array}$ & $\begin{array}{l}\text { specified activities carried out by the } \\
\text { central and local governments, } \\
\text { social welfare activities }\end{array}$ \\
\hline
\end{tabular}

Sources: Sung et al. (2012), table 3-2 (Korea); http://www.kpmg.com/Global/en/lssuesAndlnsights/ ArticlesPublications/vat-gst-essentials/pages/japan.aspx\#1 (Japan). 
Table A. 2. VAT Revenue Collection in Korea and Japan, 2004-17

(in 100 million $\# / \neq$ )

\begin{tabular}{|c|c|c|c|c|c|c|}
\hline & \multicolumn{3}{|c|}{ Korea } & \multicolumn{3}{|c|}{ Japan } \\
\hline & National & Local & Total & National & Local & Total \\
\hline 2004 & 345,718 & - & 345,718 & $101,391.46$ & $25,189.80$ & $126,581.26$ \\
\hline 2005 & 361,187 & - & 361,187 & $107,027.24$ & $26,601.45$ & $133,628.69$ \\
\hline 2006 & 380,930 & - & 380,930 & $106,735.35$ & $26,547.14$ & $133,282.49$ \\
\hline 2007 & 406,416 & - & 406,416 & $106,613.77$ & $26,531.03$ & $133,144.80$ \\
\hline 2008 & 438,198 & - & 438,198 & $103,909.63$ & $25,860.57$ & $129,770.20$ \\
\hline 2009 & 469,915 & - & 469,915 & $101,979.18$ & $25,376.13$ & $127,355.30$ \\
\hline 2010 & 491,212 & 26,789 & 518,001 & $100,468.15$ & $24,980.58$ & $125,448.73$ \\
\hline 2011 & 529,373 & 29,606 & 558,979 & $99,318.39$ & $24,723.99$ & $124,042.39$ \\
\hline 2012 & 556,676 & 30,335 & 587,011 & $99,349.13$ & $24,735.28$ & $124,084.41$ \\
\hline 2013 & 559,625 & 31,418 & 591,043 & $99,918.93$ & $24,890.17$ & $124,809.11$ \\
\hline 2014 & 571,388 & 58,357 & 629,745 & $142,731.15$ & $38,095.52$ & $180,826.67$ \\
\hline 2015 & 541,591 & 60,027 & 601,618 & $167,842.10$ & $45,121.89$ & $212,963.99$ \\
\hline 2016 & 618,282 & 64,011 & 682,293 & na & na & na \\
\hline 2017 & 670,870 & na & na & na & na & na \\
\hline
\end{tabular}

Sources: National Tax Service of Korea, National Tax Statistical Yearbook; National Tax Agency of Japan, National Tax Statistical Yearbook.

Table A. 3. Joint Distribution of Households by Age Group and Income Decile in Korea and Japan, 2014 (in \%)

\begin{tabular}{c|c|c|c|c|c|c|c|c|c|c|c}
\hline Korea & 1st & 2nd & 3rd & 4th & 5th & 6th & 7th & 8th & 9th & 10th & Total \\
\hline $\begin{array}{c}\text { 24 and } \\
\text { Under }\end{array}$ & 0.62 & 1.02 & 0.97 & 0.20 & 0 & 0 & 0.20 & 0 & 0 & 0 & 0.31 \\
\hline $25-29$ & 0 & 1.22 & 1.95 & 2.24 & 2.85 & 1.58 & 1.97 & 0.42 & 1.47 & 0.21 & 1.41 \\
\hline $30-34$ & 0.62 & 3.66 & 5.65 & 8.78 & 11.00 & 8.91 & 9.45 & 8.60 & 7.37 & 3.86 & 6.81 \\
\hline $35-39$ & 2.05 & 3.25 & 6.82 & 9.59 & 15.07 & 17.03 & 16.34 & 14.05 & 12.00 & 11.16 & 10.75 \\
\hline $40-44$ & 1.85 & 4.47 & 7.80 & 14.08 & 13.44 & 16.24 & 17.32 & 17.40 & 17.68 & 15.45 & 12.54 \\
\hline $45-49$ & 2.05 & 7.32 & 7.99 & 9.18 & 12.22 & 11.68 & 15.94 & 18.03 & 18.95 & 21.46 & 12.40 \\
\hline $50-54$ & 3.49 & 5.28 & 9.16 & 9.80 & 12.83 & 14.65 & 14.96 & 16.35 & 16.84 & 24.25 & 12.68 \\
\hline $55-59$ & 6.16 & 10.77 & 8.77 & 10.00 & 10.18 & 10.30 & 10.04 & 10.69 & 13.68 & 15.45 & 10.56 \\
\hline $60-64$ & 6.37 & 11.99 & 13.45 & 10.00 & 7.13 & 7.92 & 8.27 & 6.92 & 6.11 & 4.94 & 8.36 \\
\hline $65-69$ & 14.37 & 16.67 & 14.04 & 12.04 & 6.72 & 5.54 & 1.57 & 2.94 & 3.79 & 1.72 & 7.99 \\
\hline $70-74$ & 24.23 & 14.84 & 10.53 & 8.37 & 4.68 & 3.96 & 3.15 & 3.14 & 1.05 & 0.64 & 7.50 \\
\hline $\begin{array}{c}75 \text { and } \\
\text { Over }\end{array}$ & 38.19 & 19.51 & 12.87 & 5.71 & 3.87 & 2.18 & 0.79 & 1.47 & 1.05 & 0.86 & 8.69 \\
\hline
\end{tabular}




\begin{tabular}{c|c|c|c|c|c|c|c|c|c|c|c}
\hline Total & 100 & 100 & 100 & 100 & 100 & 100 & 100 & 100 & 100 & 100 & 100 \\
\hline Japan & 1 st & 2 2nd & 3rd & 4 th & 5 th & 6 th & 7 th & 8 th & 9 th & 10 th & Total \\
\hline $\begin{array}{c}\text { 24 and } \\
\text { Under }\end{array}$ & 1.87 & 4.75 & 3.74 & 1.65 & 1.21 & 0.28 & 0.29 & 0.11 & 0.01 & 0 & 0.36 \\
\hline $25-29$ & 1.33 & 2.79 & 3.86 & 8.48 & 5.37 & 6.18 & 2.12 & 1.15 & 1.84 & 0.37 & 1.46 \\
\hline $30-34$ & 2.60 & 2.94 & 4.08 & 4.84 & 5.82 & 11.95 & 7.42 & 6.02 & 3.48 & 1.40 & 6.90 \\
\hline $35-39$ & 1.38 & 2.03 & 2.69 & 3.44 & 6.59 & 9.34 & 10.86 & 9.69 & 6.76 & 4.71 & 11.90 \\
\hline $40-44$ & 2.10 & 2.67 & 4.70 & 6.75 & 6.60 & 9.53 & 13.93 & 15.95 & 12.89 & 10.17 & 13.53 \\
\hline $45-49$ & 3.67 & 3.00 & 4.41 & 3.08 & 5.16 & 6.83 & 10.52 & 14.22 & 15.03 & 13.66 & 13.08 \\
\hline $50-54$ & 5.00 & 3.36 & 3.68 & 3.23 & 5.22 & 6.09 & 7.30 & 12.41 & 16.36 & 19.66 & 12.13 \\
\hline $55-59$ & 7.31 & 4.99 & 4.95 & 4.27 & 7.61 & 6.58 & 9.98 & 10.44 & 16.78 & 20.18 & 10.04 \\
\hline $60-64$ & 12.09 & 10.95 & 9.41 & 9.23 & 10.70 & 12.19 & 10.47 & 10.29 & 9.99 & 11.52 & 7.92 \\
\hline $65-69$ & 16.61 & 16.58 & 16.56 & 14.97 & 14.13 & 12.29 & 10.86 & 9.48 & 7.80 & 8.96 & 7.62 \\
\hline $70-74$ & 16.63 & 18.31 & 17.35 & 16.35 & 14.20 & 9.99 & 8.19 & 5.46 & 5.09 & 5.42 & 7.22 \\
\hline $\begin{array}{c}75 \text { and } \\
\text { Over }\end{array}$ & 29.42 & 27.63 & 24.57 & 23.72 & 17.39 & 8.75 & 8.06 & 4.78 & 3.97 & 3.94 & 7.83 \\
\hline Total & 100 & 100 & 100 & 100 & 100 & 100 & 100 & 100 & 100 & 100 & 100 \\
\hline
\end{tabular}

Note: These numbers are based on the author's own calculation using the HIES for Korea and table 14-1 of the NSFIE for Japan (http://www.stat.go.jp/english/data/zensho, April, 27, 2018).

Table A. 4. Effective VAT Rates by Age of Household Heads in Korea, 2006-14 (in \%)

\begin{tabular}{l|c|c|c|c|c|c|c|c|c|c|c}
\hline & $\begin{array}{c}24 \text { and } \\
\text { Under }\end{array}$ & $\begin{array}{c}25- \\
29\end{array}$ & $\begin{array}{c}30- \\
34\end{array}$ & $\begin{array}{c}35- \\
39\end{array}$ & $\begin{array}{c}40- \\
44\end{array}$ & $\begin{array}{c}45- \\
49\end{array}$ & $\begin{array}{c}50- \\
54\end{array}$ & $\begin{array}{c}55- \\
59\end{array}$ & $\begin{array}{c}60- \\
64\end{array}$ & $\begin{array}{c}65 \\
\text { and } \\
\text { Up }\end{array}$ & Average \\
\hline 2006 & 3.52 & 3.51 & 3.53 & 3.55 & 3.57 & 3.33 & 3.25 & 2.99 & 2.86 & 2.55 & 3.30 \\
\hline 2007 & 3.50 & 3.65 & 3.44 & 3.42 & 3.58 & 3.39 & 3.18 & 3.10 & 2.78 & 2.58 & 3.27 \\
\hline 2008 & 3.73 & 3.51 & 3.33 & 3.43 & 3.49 & 3.39 & 3.10 & 3.08 & 2.93 & 2.64 & 3.24 \\
\hline 2009 & 3.37 & 3.70 & 3.57 & 3.78 & 4.05 & 3.72 & 3.45 & 3.07 & 3.22 & 2.56 & 3.53 \\
\hline 2010 & 3.61 & 4.04 & 3.54 & 3.34 & 3.22 & 3.19 & 3.26 & 3.06 & 3.12 & 2.71 & 3.22 \\
\hline 2011 & 4.40 & 3.86 & 3.76 & 3.37 & 3.27 & 3.28 & 3.26 & 3.22 & 3.07 & 2.79 & 3.27 \\
\hline 2012 & 3.49 & 4.32 & 4.00 & 3.75 & 3.58 & 3.60 & 3.61 & 3.67 & 3.54 & 3.03 & 3.59 \\
\hline 2013 & 3.70 & 4.88 & 3.93 & 3.67 & 3.68 & 3.57 & 3.45 & 3.48 & 3.48 & 2.88 & 3.53 \\
\hline 2014 & 3.34 & 4.15 & 3.93 & 3.86 & 3.69 & 3.47 & 3.49 & 3.52 & 3.54 & 2.93 & 3.54 \\
\hline
\end{tabular}

Note: All figures are based on author's own calculations, which are derived from the HIES. 
Table A. 5. Suits Index Measure of Progressivity of VAT Burden in Korea, 1982-2014

\begin{tabular}{|c|c|c|}
\hline & $\begin{array}{l}\text { Urban Households with Two or } \\
\text { More Residents }\end{array}$ & All Households \\
\hline 1982 & 0.01147 & \\
\hline 1983 & 0.00660 & \\
\hline 1984 & -0.00257 & \\
\hline 1985 & 0.00102 & \\
\hline 1986 & -0.00314 & \\
\hline 1987 & -0.02063 & \\
\hline 1988 & 0.01074 & \\
\hline 1989 & 0.04162 & \\
\hline 1990 & 0.04921 & \\
\hline 1991 & 0.03452 & \\
\hline 1992 & 0.02399 & \\
\hline 1993 & 0.01487 & \\
\hline 1994 & 0.01548 & \\
\hline 1995 & -0.00449 & \\
\hline 1996 & -0.00732 & \\
\hline 1997 & -0.03920 & \\
\hline 1998 & -0.07288 & \\
\hline 1999 & -0.02042 & \\
\hline 2000 & -0.03355 & \\
\hline 2001 & -0.03801 & \\
\hline 2002 & -0.04590 & \\
\hline 2003 & -0.05383 & \\
\hline 2004 & -0.05925 & \\
\hline 2005 & -0.05458 & \\
\hline 2006 & -0.04994 & -0.04115 \\
\hline 2007 & -0.05287 & -0.04177 \\
\hline 2008 & -0.06293 & -0.04951 \\
\hline 2009 & -0.02642 & -0.01021 \\
\hline 2010 & -0.07085 & -0.05931 \\
\hline 2011 & -0.07192 & -0.05954 \\
\hline 2012 & -0.06491 & -0.05642 \\
\hline 2013 & -0.05895 & -0.05028 \\
\hline 2014 & -0.05062 & -0.04124 \\
\hline
\end{tabular}

Notes: 1. All figures are based on author's own calculations, which are derived from the HIES.

2. The Suits index lies between -1 and 1 . If it is positive, the tax burden is progressive, if it is negative, it is regressive, and if it is 0 , is it neutral. The larger its absolute value, the larger the progressivity or regressivity of the tax. 
Table A. 6. Progressivity of Several Selected Taxes in Korea and Their Effect on Income Redistribution, 2014

\begin{tabular}{l|l|c|c}
\hline & & $\begin{array}{c}\text { Suits } \\
\text { Index }\end{array}$ & $\begin{array}{c}\text { Effects on Income } \\
\text { Redistribution (\%) }\end{array}$ \\
\hline Personal Income Tax & $\begin{array}{l}\text { wage/salary/business income } \\
\text { tax (A) }\end{array}$ & 0.37303 & 3.32 \\
\hline & $\begin{array}{l}\text { (A) + dividend and interest } \\
\text { income tax }\end{array}$ & 0.36782 & 3.31 \\
\hline Property Tax & & -0.08412 & -0.08 \\
\hline Public Pension Contributions & & 0.09619 & 0.83 \\
\hline National Health Insurance & & 0.03688 & 0.39 \\
\hline Fees & & -0.03914 & -0.2 \\
\hline Total Consumption Taxes & & -0.04124 & -0.18 \\
\hline VAT & & 0.05145 & 0.06 \\
\hline Excise Taxes & & 0.00320 & 0.12 \\
\hline Gasoline and Diesel Oil Tax & & -0.15628 & -0.03 \\
\hline Liquor Tax & & -0.29829 & -0.17 \\
\hline Tobacco Tax & & 0.06 & \\
\hline
\end{tabular}

Notes: 1. All figures are based on author's own calculations, which are derived from the HIES.

2. The Suits index lies between -1 and 1 . If it is positive, the tax burden is progressive, if it is negative, it is regressive, and if it is 0 , is it neutral. The larger its absolute value, the larger the progressivity or regressivity of the tax.

3.The effect of income redistribution is measured in percentage decreases in Gini coefficients between pre- and posttax incomes.

4. The gasoline and diesel oil, liquor, and tobacco tax include surtaxes. 
